ISSN 2072-4292

www.mdpi.com/journal/remotesensing

Review

\title{
Mapping Surface Broadband Albedo from Satellite Observations: A Review of Literatures on Algorithms and Products
}

\author{
Ying Qu ${ }^{1,2, *}$, Shunlin Liang ${ }^{1,2,3}$, Qiang Liu ${ }^{1,2}$, Tao He ${ }^{3}$, Suhong Liu ${ }^{1,4}$ and Xiaowen Li ${ }^{1,4}$
}

1 State Key Laboratory of Remote Sensing Science, Beijing Normal University, Beijing 100875, China; E-Mails: toliuqiang@bnu.edu.cn (Q.L.); lix@bnu.edu.cn (X.L.)

2 College of Global Change and Earth System Science, Beijing Normal University, Beijing 100875, China

3 Department of Geographical Sciences, University of Maryland, College Park 20742, MD, USA; E-Mail: sliang@umd.edu (S.L.); the@umd.edu (T.H.)

4 School of Geography, Beijing Normal University, Beijing 100875, China;

E-Mail: liush@bnu.edu.cn

* Author to whom correspondence should be addressed; E-Mail: quying@ bnu.edu.cn; Tel.: +86-010-5880-4501; Fax: +86-010-5880-2165.

Academic Editors: Richard Gloaguen and Prasad S. Thenkabail

Received: 8 October 2014 / Accepted: 5 January 2015 / Published: 16 January 2015

\begin{abstract}
Surface albedo is one of the key controlling geophysical parameters in the surface energy budget studies, and its temporal and spatial variation is closely related to the global climate change and regional weather system due to the albedo feedback mechanism. As an efficient tool for monitoring the surfaces of the Earth, remote sensing is widely used for deriving long-term surface broadband albedo with various geostationary and polar-orbit satellite platforms in recent decades. Moreover, the algorithms for estimating surface broadband albedo from satellite observations, including narrow-to-broadband conversions, bidirectional reflectance distribution function (BRDF) angular modeling, direct-estimation algorithm and the algorithms for estimating albedo from geostationary satellite data, are developed and improved. In this paper, we present a comprehensive literature review on algorithms and products for mapping surface broadband albedo with satellite observations and provide a discussion of different algorithms and products in a historical perspective based on citation analysis of the published literature. This paper shows that the observation technologies and accuracy requirement of applications are important, and long-term, global
\end{abstract}


fully-covered (including land, ocean, and sea-ice surfaces), gap-free, surface broadband albedo products with higher spatial and temporal resolution are required for climate change, surface energy budget, and hydrological studies.

Keywords: surface albedo; Bidirectional Reflectance Distribution Function (BRDF); remote sensing; surface energy budget; Global Land Surface Satellite (GLASS)

\section{Introduction}

Surface albedo is a critical geographical parameter that is widely used in studies of surface energy budget, numerical weather forecast, and general circulation models [1]. The surface broadband albedo is defined as the ratio of the surface upwelling to the downward flux of shortwave solar radiation over the upward semi-hemispherical space [2] (Figure 1). It is one of the controlling parameters of the surface energy budget equation [3], which affects the input and relocation of solar energy over the Earth's surfaces $[4,5]$.

The global land surface albedo changes with natural processes and human activities [6], such as deforestation [7,8], desertification [9], wildfire [10], and the decreasing of northern-hemisphere snow and sea-ice [11-13]. These changes in surface albedo also influence regional and global weather [14] in which even tiny variations of surface albedo can feedback to the climate system and affect the global and regional climate patterns. For example, the albedo-drought feedback mechanism [15-18] and snow/sea-ice albedo feedback mechanism $[19,20]$ have been studied for decades, and the results show that albedo plays an important role in global climate change.

The spatial and temporal variation of surface albedo is closely related to global climate change and regional weather systems [21]. In many climate and land process models, the value of surface albedo is usually assigned by land cover types or generated by the simple relationship between surface albedo and the solar zenith angle, as well as with other ancillary variables [22,23]. The comparison of the surface broadband albedo derived from different models shows that different models compute surface albedo differently and that the spread of the modeled albedo can be as large as $0.15-0.19$ in the high-latitude region of the northern hemisphere [24]. Therefore, it is not sufficient to describe the changes in the global surface albedo with model-simulated data only, and long-term surface albedo products with high spatial and temporal resolution are required by the global climate change studies. As an efficient tool for monitoring the surfaces of the Earth, remote sensing is widely used for deriving long-term surface broadband albedo with various geostationary and polar-orbit satellite platforms in the recent decades. There are more and more climate studies that use surface albedo products generated from satellite observations as forcing data [25,26]. For climate change studies, the demanded accuracy of the surface albedo product is approximately 0.02-0.05 within 5-10 years on a global scale [21,27], and a sensitivity analysis shows that an absolute albedo accuracy less than \pm 0.02 is required by the regional climate simulations [28].

From the 1980s to the present, many algorithms for estimating surface broadband albedo from satellite data have been developed, and various surface albedo products were generated with satellite data. The related studies change rapidly with the development of satellite observation technologies, and the scientists who major in global climate change, surface energy budget, and hydrology are highly concerned because of this. Thus, it is necessary to provide a literature review of the current algorithms 
and products, which will arouse the broad interests of both algorithm developers and users of the surface broadband albedo products.
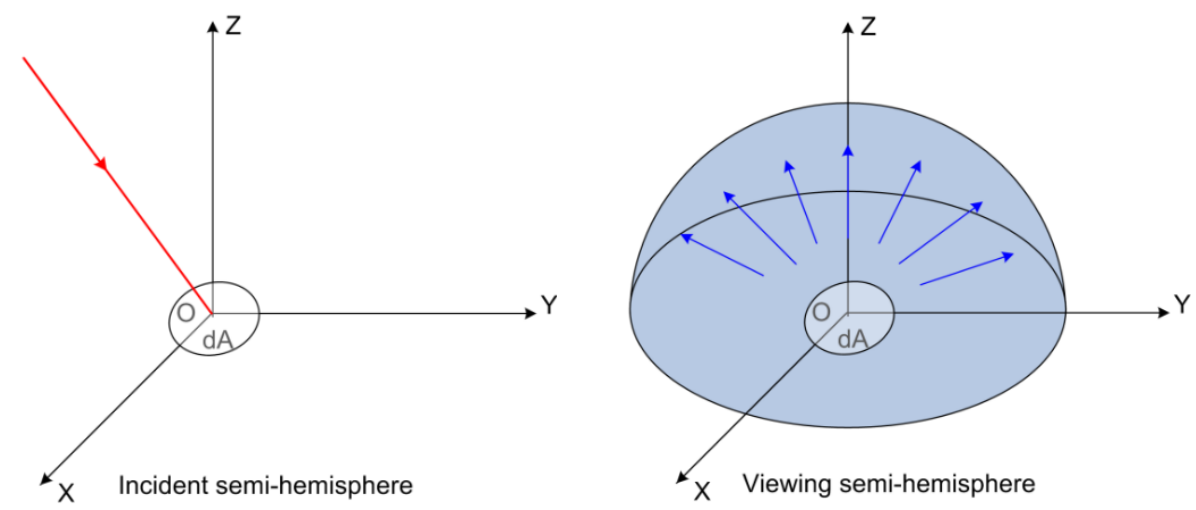

(a)
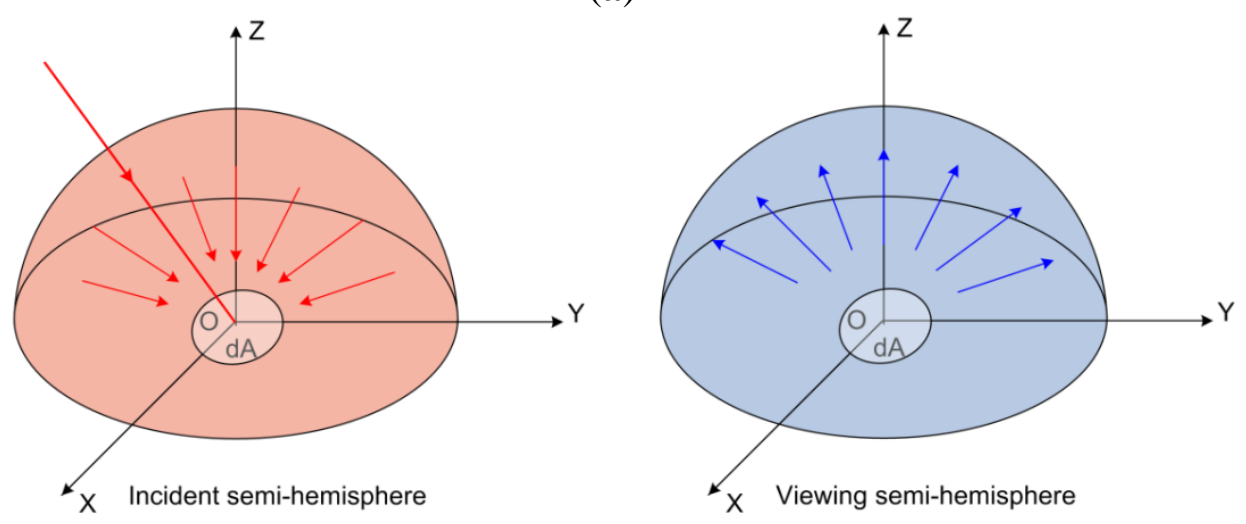

(b)

Figure 1. Definitions of the surface albedo. (a) Black-sky albedo; (b) White-sky albedo. The red lines indicate the incident directions and the blue lines indicate the viewing directions.

In this paper, we present a comprehensive review of the literature on algorithms and products for mapping surface broadband albedo with satellite observations. This paper is organized as follows: First, we provide a historical review of the literature on remote sensing of the surface broadband albedo based on statistical and citation analysis tools in Section 2. Then, we provide a brief description and discussion about the algorithms in Section 3. In Section 4, we provide a list and comparison of the current widely used surface albedo products generated from remote sensing data. Finally, we provide a brief summary of this review in Section 5.

\section{Literature Analysis}

Citation analysis is one of the best ways for people to understand how the research developed, what the most important issues are, and what may be potential hotspots for future studies. The statistical results and a citation relationship figure may help us to have a clearer understanding of the timeline and milestones of this subject. In this paper, we searched the articles that contain "albedo" in the title through the website of the Web of Science ${ }^{\mathrm{TM}}$, Thomson Reuter. To exclude studies of planetary albedo, single scattering albedo, top of atmosphere (TOA) albedo, and cloud albedo, we further screened the searched 
results by subject and keywords. Finally, the papers about the remote sensing of surface albedo were collected from the Web of Science platform for citation statistics and analysis.

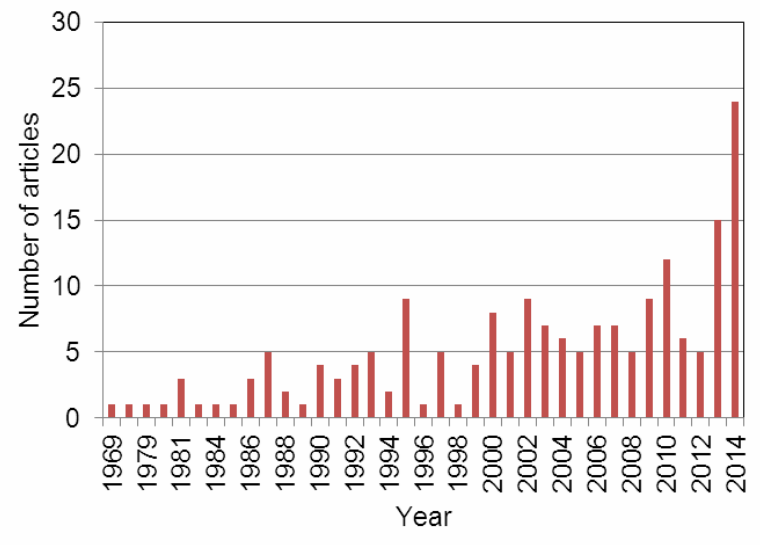

(a)

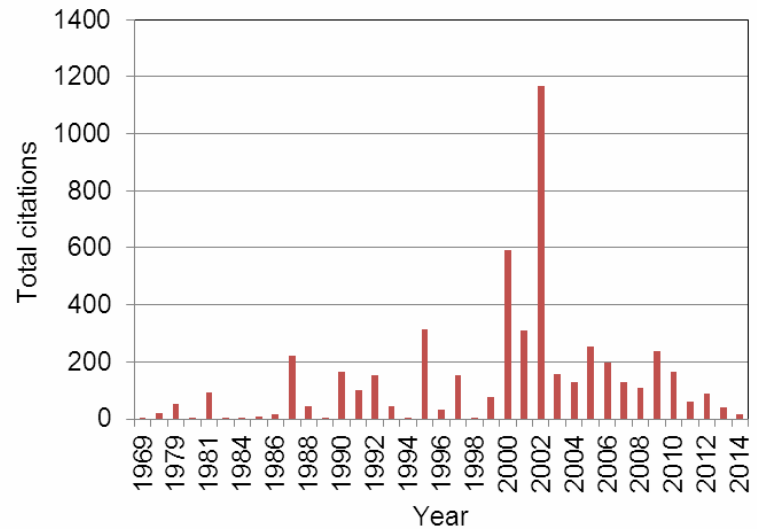

(b)

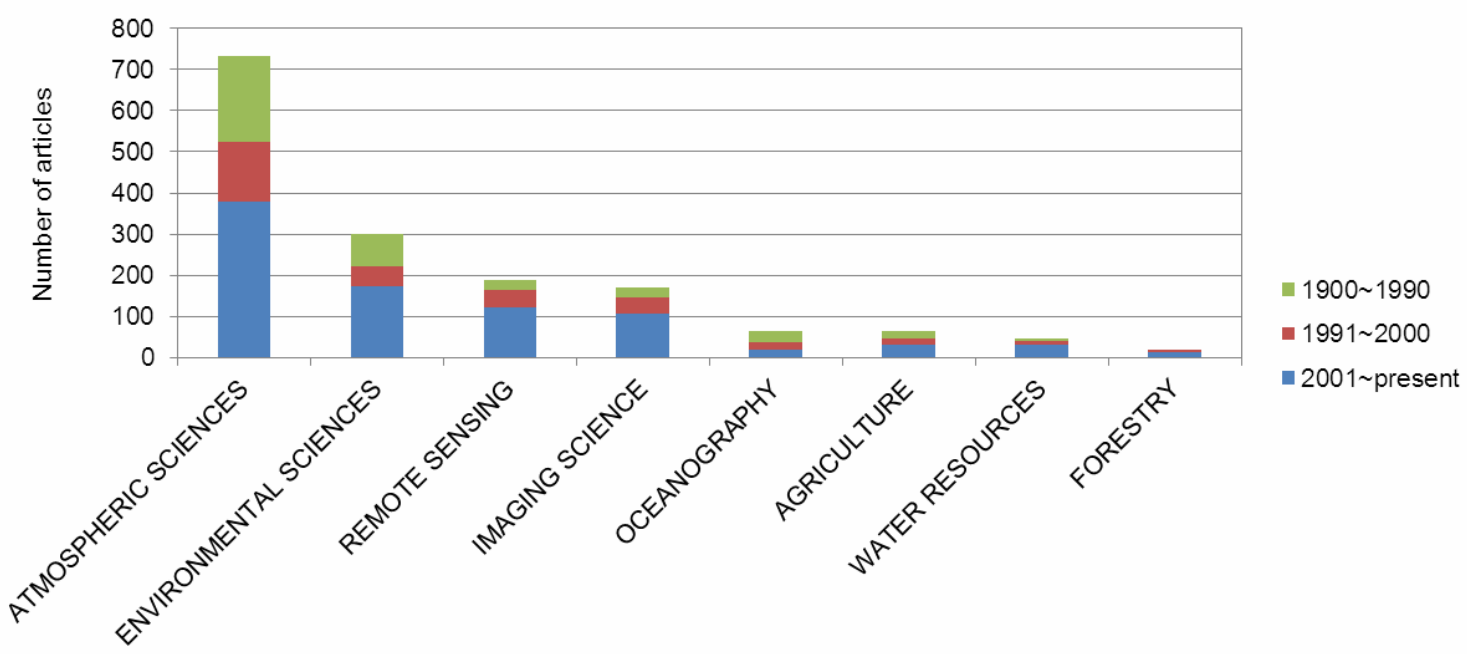

(c)

Figure 2. Citation statistics of mapping surface broadband albedo from satellite data. (a) The number of published articles from 1969 to 2012. (b) The total citations from 1969 to 2012. (c) The articles contributed by different research field in recent decades.

Figure 2 shows the citation statistics of estimating surface broadband albedo from satellite data. Figure 2a,b shows the total publications and citations from 1969 to 2012. Both the numbers of publications and citations grow year by year, and the publication peak years are 1995, 2002, 2010 and 2014, while the citations peak years are 1995, 2000, and 2002. However, the papers published after 2002 have not been widely cited because the published years are too recent. Figure $2 \mathrm{c}$ shows the articles contributed by different research field in recent decades. Before 1990, most of the studies were contributed by atmospheric sciences in which the surface albedo was used as forcing data of global climate models (GCM) and numerical weather forecast (NWF) models. The studies on the albedo feedbacks and spatial/temporal variations were also carried out. In recent two decades, the atmospheric sciences is still the top field that contributes to this topic and more and more articles of environmental sciences, remote sensing, and imaging sciences were published. In addition, there are also many studies 
of oceanography, agriculture, water resources, and forestry since 1990s, such as the relationship between albedo and evapotranspiration, land cover/land use, carbon cycle.

The citation relationship analysis is carried out by the HistCite software, Thomson Reuters. The results are shown in Figure 3. Kriebel [29] first proposed the method for estimating the surface albedo of the vegetation canopy by a field measured Bidirectional reflectance factor (BRF). Eight years later, Kimes et al. [30] analyzed the estimation bias with a nadir-view reflectance based on the radiative transfer model and declared that it is important to estimate land-surface albedo with multiple-angular satellite observations. Subsequently, Irons et al. [31] also presented a study of estimating canopy albedo with the BRF data, while Ranson et al. [32] and Starks et al. [33] proposed prototype algorithms for estimating the surface albedo with multiple-angular remote sensing data.

In addition to the studies for estimating surface albedo with multiple-angular remote sensing data (right branch of Figure 3, labeled in blue), another method for estimating broadband albedo with narrow-to-broad band conversions is also developed (left branch of Figure 3, labeled in red) simultaneously. Brest and Goward [34] first provided the concept of the narrow-to-broadband conversion method for estimating surface albedo. Then, this method was applied to Advanced Very High Resolution Radiometer (AVHRR) [35,36], Landsat Thematic mapper (TM) [37,38], and Meteosat [39].

In the late 1990s, few papers (for example, validation of albedo products derived from AVHRR [40] and symmetry of diurnal albedo cycle [41]) that are highly cited were published. The main reason for this phenomenon is the lack of a stable multiple-angular satellite platform, which demonstrates that the observing technology is important for this subject.

Since the Moderate Resolution Imaging Spectroradiometer (MODIS) onboard the Terra satellite launched in 2000, the studies of estimating land-surface albedo with remote sensing data entered into a new era. Lucht et al. [42] estimated the land-surface albedo with a semi-empirical linear kernel-driven model. This paper, with a series of relative studies [43-45], established the foundation of estimating surface albedo with bidirectional reflectance distribution function (BRDF) modeling. Subsequently, Schaaf et al. [46] presented the algorithm and preliminary results of the MODIS BRDF/albedo product, which became the most cited paper in this subject. In addition, Liang [47] summarized the former studies for estimating surface broadband albedo based on narrow-to-broadband conversions and provided easy-to-use narrow-to-broadband conversion coefficients for typical remote sensing sensors with a spectral reflectance library and the Santa Barbara DISORT Atmospheric Radiative Transfer (SBDART) [48] simulations. The above-mentioned three papers published in 2000-2002 became the top cited papers and still have great influence on the current studies, which can be considered as milestones of this subject.

From 2002 to now, researchers paid more attention to the improvement and validation of the current surface albedo products [49-53]. In this period, the highlighted papers include the algorithm for the snow albedo product [54] and the direct-estimation algorithm [55] (labeled with green in Figure 3). 


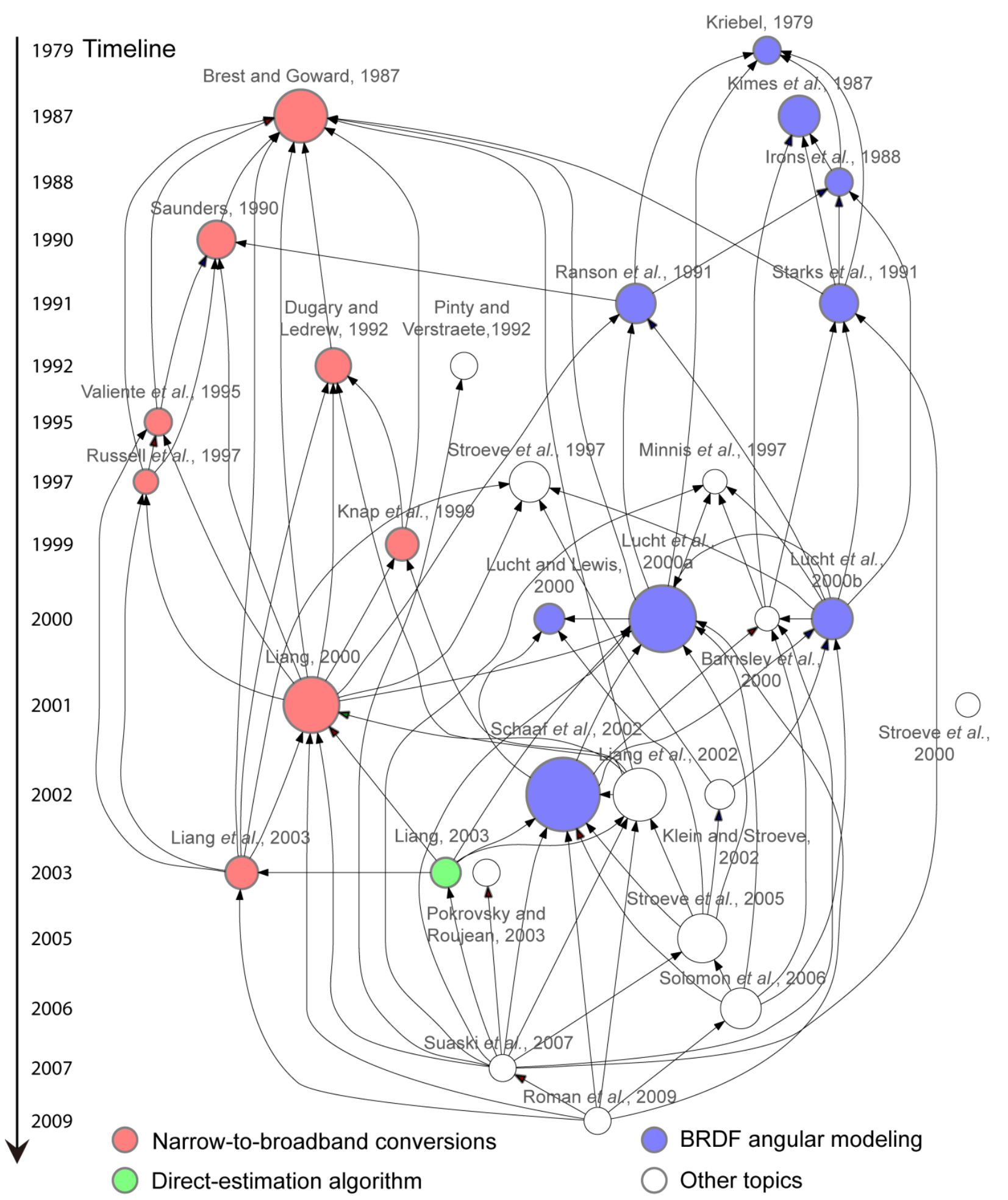

Figure 3. Citation relationship figure for mapping surface broadband albedo with satellite data, where the radius of the circle stands for the total citations of its corresponding literature; the vertical axis stands for the timeline (the published year for each study), the horizontal axis stands for the similarity of papers; the arrow pointing to the circle stands for its corresponding paper, which is cited by the consequent papers; the color of circle indicates the themes of articles: narrow-to-broadband conversions (red), BRDF angular modeling (blue), direct-estimation algorithm (green) and other topics (white). 
With the aid of citation statistics and a relationship figure, we provide a review of estimating surface albedo with satellite data. At the beginning, there are mainly two branches of research that focus on angular and spectral integrations, respectively. From the 1980s to the 1990s, the algorithms for estimating surface albedo were improved and applied to different field and satellite data; however, the lack of a stable multi-angular satellite observation platform restrained the development of this subject. Thanks to the Earth Observing System (EOS) project, more and more satellites with multi-angular viewing capabilities have been launched, leading to a sudden increase in the number of published papers. Meanwhile, these two branches of studies became much more closely connected, and various surface broadband albedo products estimated by satellite observations were derived during this time. In the new century, the direct-estimation algorithm became a new growth point of the estimating algorithm, and the validation and evaluation of current surface broadband products became a hot topic in this scope. Based on the literature review and analysis, we can conclude that observation techniques and application demand are important for this subject. On one hand, the observation techniques are fundamental for realizing new algorithms for mapping surface broadband albedo, which can be demonstrated by the publication and citation peak year around the year 2002. It also can be foreseen that there would be more and more papers published with the new sensors and platform (such as the NPOESS Preparation Project (NPP), Joint Polar Satellite System (JPSS), Sentinel-3 under European Copernicus project, and China's Gaofen satellite project). On the other hand, the accuracy requirement of the application is also critical for the remote sensing of surface albedo, and better, more accurate albedo products are demanded by the different applications.

\section{Algorithms}

A traditional algorithm for estimating surface broadband from polar-orbit satellite observations consists of three steps: atmospheric correction, narrow-to-broadband conversions and BRDF angular modeling. For most cases, the narrow-to-broadband conversions and BRDF angular modeling are the two major components in the processing chain, which focus on spectral and angular integration, respectively (detailed information about these processes is described in the Appendix). Based on the review of the literature, different studies are concerned with different components. The implemented steps and relationships of these algorithms are shown in Figure 4.

\subsection{Narrow-to-Broadband Conversions}

When the land surface is assumed as lambertian (the reflectance is isotropic from different solar/view angles), the value of BRF is then equal to the albedo and the surface broadband albedo can be estimated from linear combinations of narrowband albedo (spectral hemispherical reflectance) with different weight coefficients. This method was first proposed by Brest and Goward [34] and was then applied to different sensors: AVHRR [35,36], Landsat TM [37,38], Meteosat [39] and Visible Infrared Imaging Radiometer Suite (VIIRS) [56]. Liang [47] reviewed the above studies and provided simple conversion coefficients for estimating broadband surface albedo from a variety of sensors under different atmospheric and surface conditions. The validation results show that the conversion formulae are very accurate with an average residual standard error around 0.02 [50]. There are also some studies provide the narrow-to-broadband conversion coefficients for snow [52] and sea-ice [57]). 


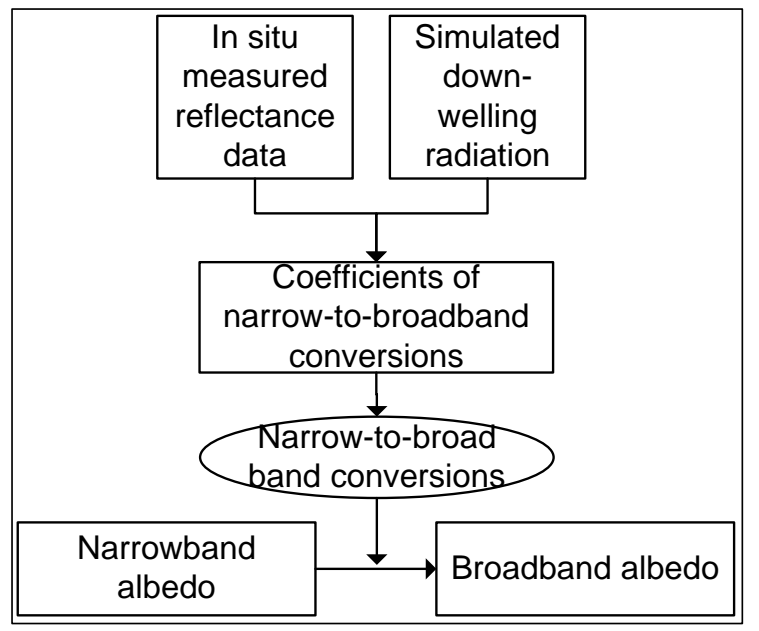

(a)

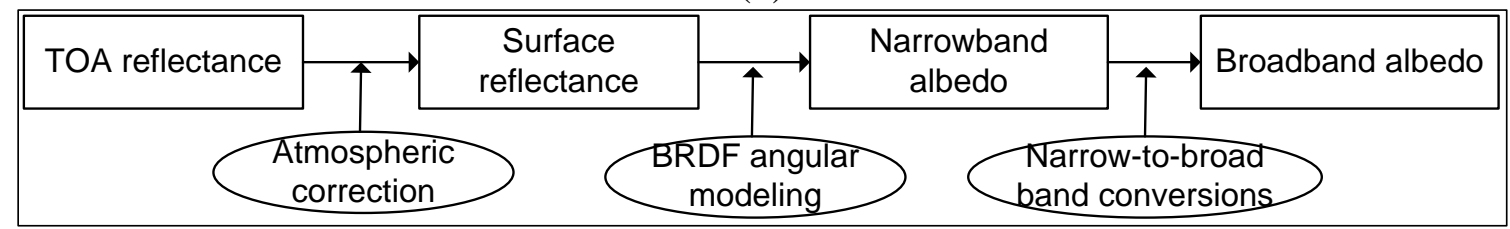

(b)

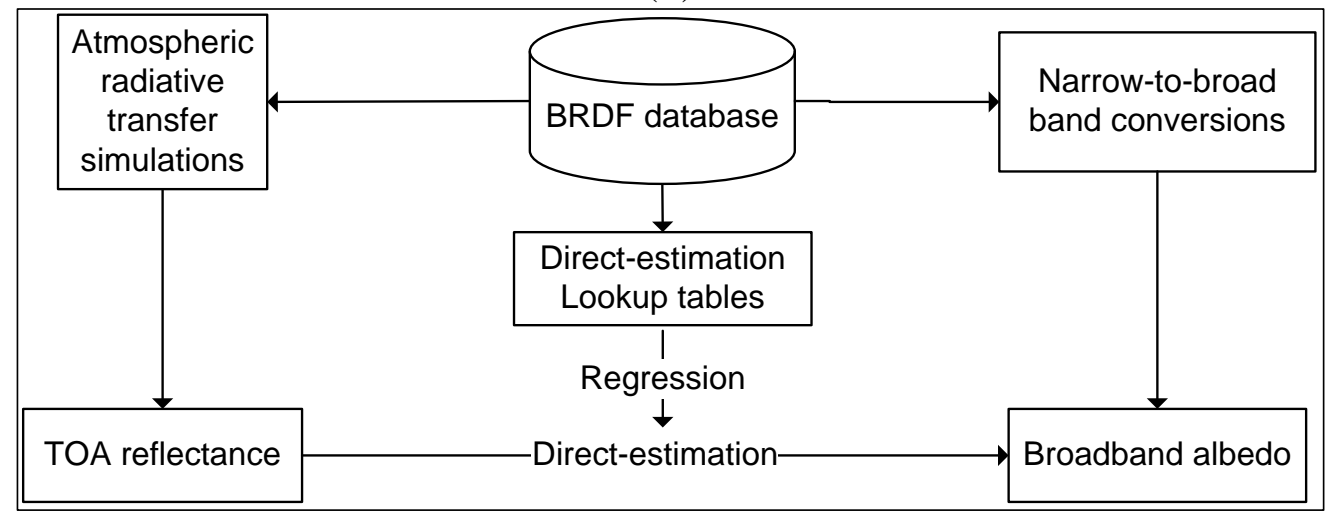

(c)

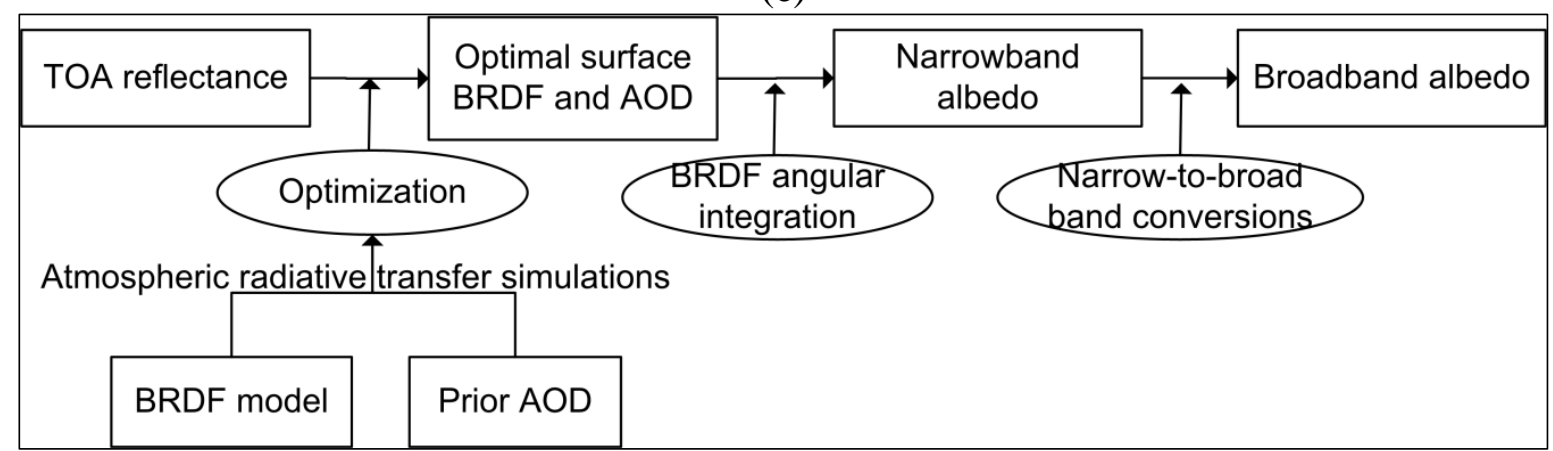

(d)

Figure 4. Flow chart of the algorithms for estimating surface broadband albedo from satellite observations. (a) Narrow-to-broadband conversions; (b) BRDF angular modeling; (c) Direct-estimation algorithm; (d) Estimating albedo from geostationary satellite data.

The overall implementation steps of the narrow-to-broadband conversions are shown in Figure 4a. The narrow-to-broadband conversion coefficient is first derived with the in situ measured spectral reflectance library and solar radiative fluxes simulated by the atmospheric radiative transfer models. 
Then, the derived coefficients are applied to convert narrowband BRF to surface broadband albedo. The narrow-to-broadband conversion coefficients are also used as a part of the algorithm based on BRDF angular modeling and the direct-estimation algorithm.

\subsection{BRDF Angular Modeling}

When the surface reflects differently with different solar and view angles, the hemispherical reflectance (albedo) cannot be estimated from a singular observation, so it is necessary to build a BRDF angular model for describing the reflectance anisotropy effect of the land/ocean surfaces (right branch of Figure 3). Once the BRDF is fitted by empirical or semi-empirical kernel functions with multi-angular satellite observations, the black and white-sky albedo can be calculated by an integration of BRDF over the solar/view semi-hemisphere. The estimation results are much more accurate than those estimated by the method based on the lambertian assumption, especially when the reflectance changes dramatically with different solar/view angles. In the past decades, the ray-tracing models, radiative transfer models, analytical models based on approximations of the radiative transfer and empirical models are used for describing the surface BRDF [58]. Among them, the semi-empirical models are favored in albedo modeling for their simply form as well as flexibility. In the year of 1992, Roujean et al. [59] proposed a semi-empirical linear kernel-driven model, which enable the description of the reflectance anisotropy by using linear combinations of isotropic, geo-optical, and volume-scattering kernels. Later on, the most well-known algorithm based on the linear kernel-driven model is proposed by Lucht et al., which is usually called the Algorithm for MODIS Bidirectional Reflectance Anisotropy of the Land Surface (AMBRALS) [42]. The AMBRALS is applied to generating the MODIS BRDF/Albedo products by Schaaf et al. [46], which can estimate the land surface albedo of land surfaces (1-km spatial resolution, 8-day temporal resolution) with clear sky, multi-bands, multi-angular MODIS reflectance data during a 16-day observation cycle. Recently, the daily surface broadband albedo product (MCD43A) is also being generated using a 16-day rolling method [60,61]. In these studies, the Ross-Thick and Li-Sparse-R kernel functions are employed for fitting a multi-angular observed BRF. The Ross-Li kernel model does not perform well in the hotspot situation. Maignan et al. [58] proposed a modified Ross-Li kernel functions with consideration of the hotspot effect, which can accurately represent the sharp reflectance increase in the hotspot direction.

The processing chain of the algorithms that focuses on BRDF angular modeling can be simply separated into three steps (Figure 4b): atmospheric correction, BRDF angular modeling, and narrow-to-broadband conversions.

\subsection{Direct-Estimation Algorithm}

The direct-estimation algorithm is a method for mapping surface broadband albedo from the top of atmosphere (TOA) reflectance of satellite observations directly [55]. Compared with the algorithms based on multi-date/angular observations $[42,46]$, the direct-estimation algorithm enables the estimation of surface broadband albedo based on a single-date/angular observation, which is more capable of characterizing the temporal variation of surface albedo, especially when the surface BRDF changes rapidly [62]. Liang first proposed the direct-estimation algorithm with a lambertian spectral library based on a neural network (NN) [63] and projection pursuit regression (PPR) methods [55]. In a subsequent 
study, Liang et al. [64] used the Discrete-Ordinate Radiative Transfer (DISORT) model for simulating the surface BRDF of snow/ice and applied an angular bin regression for estimating surface broadband albedo over the Greenland ice sheet. The BRDF database of this algorithm was further improved and applied to the MODIS [65] and Polarization and Directionality of the Earth's Reflectances (POLDER) BRDF database $[62,66]$. The direct-estimation algorithm has also been applied to other satellite sensors, such as the Advanced Land Imager (ALI) of EO-1 [67] and the Airborne Visible Infrared Imaging Spectrometer (AVIRIS) data [68]. In addition, the direct-estimation algorithm has in common with the joint optimal method. Both of them estimate surface albedo from TOA measurements directly. The main difference between them is that the joint optimal methods do not use prior BRDF database. Instead, the Rahman-Pinty-Verstraete (RPV) [69] BRDF model and radiative transfer model (RTM) are used for inverting from multi-angular TOA measurements.

The flowchart of the direct-estimation algorithm is shown in Figure 4c. First, a prior BRDF database is built based on field-measured or model-simulated data. Then, a training dataset with TOA BRF and its corresponding surface broadband albedo is derived from the following processing steps: atmospheric radiative transfer, BRDF angular modeling, and narrow-to-broadband conversions. Finally, a relationship between the TOA BRF and surface broadband albedo is established, enabling the estimation of the surface broadband albedo with a single-angular observation.

\subsection{Estimating Albedo from Geostationary Satellite Data}

Compared with the studies on estimating surface albedo from polar-orbit satellite data, the algorithm for generating albedo products from geostationary data are quite different. The geostationary meteorological satellite can provide observations with high temporal resolution in a geosynchronous orbit, which are the only available platforms (apart from the AVHRR instrument) that can be used to retrieve surface albedo from the early 1980s [70]. The geostationary satellites have the advantage of acquiring data for the same surface target many times per day and providing daily multi-angular sampling dataset [71].

Unlike the multi-spectral polar-orbit satellites, some sensors onboard geostationary satellites, such as the Meteosat Visible and Infrared Imager (MVIRI), do not have a near-infrared band. The absence of the near-infrared bands from these sensors makes it difficult to use the classic atmospheric correction method. Thus, it is only possible to estimate surface reflectance when the atmospheric impact (e.g., aerosol scattering) is low.

For addressing this issue, Knapp et al. [72] proposed a temporal composite method to deal with the single band Geostationary Operational Environmental Satellite (GOES) data. In this study, the impacts of cloud and aerosol over vegetated pixels are minimized by selecting the darkest observation within a temporal window. With the development of multi-spectral geostationary sensors, such as the Spinning Enhanced Visible and Infrared Imager (SEVIRI) onboard the Meteosat Second Generation (MSG) can be used for estimating surface broadband albedo. The temporal composite approach was extended by considering the diurnal variation in surface reflectance and applied along with SEVIRI to estimate aerosol properties [73]. However, the surface reflectance was negatively biased because more observations provide more opportunities for darker observations and cloud shadows. As a result, the aerosol optical depth (AOD) retrievals have a positive bias. To mitigate this issue, the current SEVIRI 
surface albedo algorithm [74] employs an empirical formulation of latitude to estimate the AOD and integrates the atmospherically corrected reflectance to obtain the daily albedo product. For applying the "dark object" atmospheric correction method to multi-spectral geostationary data, the surface spectral BRF shape needs to be predefined [72]. In these studies, the MODIS albedo data were also employed as the first guess. To better account for the interaction between the atmosphere and the surface reflectance, Govaerts et al. [75] proposed a joint optimal algorithm to retrieve the surface BRF and daily invariant AOD simultaneously, which is similar to the previous approach designed for the MVIRI albedo [76]. In this algorithm, the BRF from the preceding day is used as prior information to control the separation of the surface contribution from that of the atmosphere. The atmospheric correction was shown to have an accuracy equivalent to that of the MODIS products, within 20\% of the AOD values. To improve the temporal resolution of the AOD estimation, Mei et al. [77] developed an algorithm to simultaneously retrieve the AOD and surface reflectance by assuming that both the aerosol and the surface reflectance are stable in the three consecutive SEVIRI observations, which shows good agreement with in situ measurements.

One of the most challenged issues for generating surface albedo from geostationary satellite data is how to generate consistent estimations from different sensors/platforms. Efforts have been made to derive surface albedo from adjacent Meteosat satellites [78], which estimate consistent results in the overlapped area with acceptable difference. A global geostationary surface albedo map has been derived from five different geostationary satellites (Meteosat-7, Meteosat-5, GMS-5, GEOS-10 and GOES-8) [79], which also show good agreement among the results estimated from different satellites. It is also necessary to account for the measurement uncertainties and differences in the Meteosat radiometer characteristics. Govaerts and Lattanzio [80] proposed a statistical method for deriving the run-time/per-pixel estimation of the uncertainty that is crucial information for detecting the real changes of surface albedo.

Figure $4 \mathrm{~d}$ shows a flowchart for estimating surface broadband albedo from geostationary satellite data. First, the surface BRDF and aerosol loadings are estimated simultaneously by the joint optimal algorithm. Then, the broadband surface albedo is derived based on the BRDF angular integration and narrow-to-broad band conversions.

\subsection{Discussion of Algorithms}

The narrow-to-broadband conversions and BRDF angular modeling focus on band and angular integrations of the surface spectral BRF, respectively. The narrow-to-broadband conversion is a fundamental algorithm for estimating surface broadband albedo from spectral albedo or BRF, which is widely applied with the single-angular observed platform when assuming lambertian surface. This method is easy-to-use for estimating broadband albedo from satellites with only a nadir-view option, which can estimate surface broadband albedo with simple linear functions. However, as the land/ocean surfaces are not lambertian in most cases, this will result in non-negligible estimation errors when the solar/view zenith angle is large, so it is not adequate to estimate the surface broadband albedo from single-angular BRF without BRDF modeling. Therefore, it is necessary to retrieve the BRDF with a multi-angular observed BRF. This BRDF angular modeling method is quite robust and physically explicit, so it is widely used for deriving a surface albedo products from satellite with multi-angular viewing capabilities. Because most of the routinely used polar-orbit satellite platforms cannot provide sufficient numbers of observations in one day (except polar regions), the current studies have to make a 
compromise: They assume that the land surface does not change rapidly in a short temporal span/window (one week, 16 days, or one month). Then, the surface BRDF/albedo is retrieved with the accumulated multi-angular observations. However, this assumption is not always valid when the BRDF characteristics of surfaces change rapidly, such as when wildfire, snow fall/melt, and harvest occur. Compared with the former two types of algorithms, the direct-estimation algorithm has a relatively short history. It provides an opportunity to correct the reflectance anisotropic effect with a prior BRDF database and enables the estimation of surface broadband albedo with a single-angular observation, which can greatly improve the temporal resolution of the surface albedo products derived from satellite observations. The disadvantage of this method is that it is much more easily affected by the sensor noises and cloud detection error, which need filtering to obtain more convincing and robust results. In addition, the prior BRDF database is very important for direct-estimation algorithm and the accuracy of the prior BRDF database would impact the albedo estimation significantly. As the surface BRDF obtained from previous retrievals and other products might vary a lot during rapid change periods like disturbance, etc., it is necessary to check the quality of the BRDF data before using it.

The algorithms for estimating albedo from geostationary satellite data can generate surface albedo products with very high temporal resolution and also provide opportunities to retrieve the surface albedo and aerosol conditions simultaneously. However, the spatial resolution of albedo products derived from geostationary satellite data is coarser than those of polar-orbit satellite data and can only cover the latitude ranges from $60^{\circ} \mathrm{S}$ to $60^{\circ} \mathrm{N}$ with missing gaps in the high latitude regions. Therefore, efforts for fusing different geostationary and polar-orbit surface albedo products should be made.

Because all of these algorithms have advantages and disadvantages at different aspects, the newly developed algorithm should overcome the problems mentioned above in the future. An alternative method may be to fuse the results estimated by different algorithms to obtain an optimal product with a better spatial/temporal resolution.

In addition to the processing chains described in Figure 4, the pre-processing steps, such as sensor calibration and cloud detection/mask, and the pre/post-processing steps, such as gap filling, topographic correction and angular normalize, are also important for deriving surface broadband albedo products with satellite observations.

\section{Products}

In recent decades, a growing number of surface broadband albedo products estimated from satellite observations have been derived. Thanks to the Earth observation projects carried out by different countries and organizations, there are more and more choices for satellite platforms and sensors for estimating surface albedo, which provides opportunities for deriving surface albedo products by collaborating observations of multiple platforms and sensors. The current widely used surface broadband albedo products $[3,81]$ are listed in Table 1 . Among the different surface albedo products, the spatial resolution ranges from $250 \mathrm{~m}$ to $20 \mathrm{~km}$, the temporal resolution ranges from daily to monthly and the temporal spans vary from 5 to 30 years.

The surface broadband albedo products estimated by polar-orbit satellites are MODIS [42,46,82], Multi-angle Imaging SpectroRadiometer (MISR) [83-86], POLDER [58,87-90], Medium Resolution Imaging Spectrometer (MERIS) [91], VEGETATION [92], POLDER [58,93], and Clouds, Albedo and 
Radiation (CLARA) [94], and those estimated by geostationary satellites are Meteosat [76,79,80,95-97] and SEVIRI $[98,99]$.

Table 1. List of current surface broadband albedo products derived from satellite observations.

\begin{tabular}{|c|c|c|c|c|c|c|}
\hline Name & Platform & $\begin{array}{l}\text { Spatial } \\
\text { Resolution }\end{array}$ & $\begin{array}{l}\text { Temporal } \\
\text { Resolution }\end{array}$ & $\begin{array}{l}\text { Temporal } \\
\text { Span }\end{array}$ & $\begin{array}{l}\text { Spatial } \\
\text { Coverage }\end{array}$ & References \\
\hline MODIS & Terra/Aqua & $1 \mathrm{~km} / 0.05^{\circ}$ & 8 days & 2000 now & $\begin{array}{l}\text { Global land } \\
\text { surface }\end{array}$ & [46] \\
\hline MISR & Terra & $0.275-1 \mathrm{~km}$ & $\begin{array}{l}\text { daily/monthly/ } \\
\text { seasonal/yearly }\end{array}$ & 2000 now & $\begin{array}{l}\text { Global land } \\
\text { surface }\end{array}$ & [83-86] \\
\hline MERIS & ENVISAT & $0.05^{\circ}$ & $\begin{array}{l}16 \text { days/ } \\
30 \text { days }\end{array}$ & 2003 now & $\begin{array}{l}\text { Global land } \\
\text { surface }\end{array}$ & [91] \\
\hline VEGETATION & SPOT & $1 \mathrm{~km}$ & 10 days & 1999 2012 & $\begin{array}{l}\text { Global land } \\
\text { surface }\end{array}$ & [92] \\
\hline POLDER & ADEOS 1-3 & $6 \mathrm{~km}$ & 10 days & $\begin{array}{l}\text { 1996 97/2003 } \\
/ 2005 \sim 2006\end{array}$ & $\begin{array}{l}\text { Global land } \\
\text { surface }\end{array}$ & {$[58,93]$} \\
\hline SEVIRI & MSG & 3 km (nadir) & 10 days & 2004 now & $\begin{array}{l}\text { Geostationary } \\
\text { disk }\end{array}$ & {$[74,98]$} \\
\hline Meteosat & GOES/GMS & $3 \mathrm{~km}$ (nadir) & 10 days & $\begin{array}{l}\text { 1981 2006 } \\
/ 1998 \sim 2007\end{array}$ & $\begin{array}{l}\text { Geostationary } \\
\text { disk }\end{array}$ & {$[70,79]$} \\
\hline CLARA & NOAA & $25 \mathrm{~km}$ & $\begin{array}{l}5 \text { days/ } \\
\text { monthly }\end{array}$ & 1982 2009 & $\begin{array}{l}\text { Global } \\
\text { land/ocean } \\
\text { surface }\end{array}$ & [94] \\
\hline GlobAlbedo & $\begin{array}{l}\text { Terra/Aqua/SPOT } \\
\text { /ENVISAT }\end{array}$ & $1 \mathrm{~km} / 0.05^{\circ}$ & 16 days & 1998 2011 & $\begin{array}{l}\text { Global land } \\
\text { surface }\end{array}$ & [100] \\
\hline GLASS & $\begin{array}{l}\text { Terra/Aqua/ } \\
\text { NOAA }\end{array}$ & $1 \mathrm{~km} / 0.05^{\circ}$ & 8 days & 1981 2012 & $\begin{array}{l}\text { Global land } \\
\text { surface }\end{array}$ & {$[62,101]$} \\
\hline
\end{tabular}

In recent years, more and more products that collaborate observations of multiple platforms and sensors, such as the Geostationary surface albedo (GSA) project within the Sustained, Coordinated Processing of Environmental Satellite Data for Climate Monitoring (SCOPE-CM) [70], GlobAlbedo [100] and the Global land surface satellite (GLASS) [101,102], were being generated. The GSA project within the SCOPE-CM [70] aims to generate reliable surface albedo product by collaborating long-term geostationary satellite data from 30 different sensors/platforms of multiple agencies. A global GSA map has been generated from five different geostationary satellites [79]. The GlobAlbedo surface albedo product was derived from collaborating the MODIS, MERIS, and VEGETATION data from 1998 to 2011, and the GLASS albedo product was derived from collaborating the AVHRR data from 1981 to 2000 and the MODIS data from 2000 to 2012. The advantages of using multi-source satellite data are as follows: (1) the multi-platform satellite data increase the number of observations, and improve the accuracy of the retrieval of the BRDF; (2) the data also minimize the uncertainty caused by estimation algorithms, cloud containments, and sensor noises; and (3) the data extend the temporal span of the surface albedo products by combining the results estimated by satellites with different life spans.

He et al. [103] compared nine satellite-based global land-surface albedo products for the period 1981-2010. The results show that most of these products are consistent, with a difference of 
approximately $0.02-0.03$ in global climatological albedo values, except for the International Satellite Cloud Climatology Project (ISCCP) and the Global Energy and Water Exchanges Project (GEWEX). The global climatologies of the GLASS, MODIS, MERIS, and GlobAlbedo datasets agree well with each other, while the CLARA shows a constant overestimation in all seasons and GlobAlbedo shows overestimation in northern winters. The consistency of satellite-based albedo datasets strongly depends on latitude. There is a better agreement in summer, while large differences were found in winter, particularly at high latitudes. In addition, the satellite-based surface albedo and snow cover extent are highly correlated, and the trends of decreasing in July and increasing in January over the northern hemisphere are likely due to the shrinking and expanding of snow cover.

\subsection{Validations of Surface Broadband Albedo Products}

Since the global surface broadband albedo products were generated, various validations of them have been carried out for evaluating the dependence on the solar zenith angle [104], robustness with the combination of terra and aqua data [105], uncertainty with the fractional of diffuse skylight [106], accuracy over high latitude snow surfaces [52,107,108] and ephemeral snowfall area [60,109], consistency [110,111], and product quality [112]. The surface in situ measured albedo datasets used for validating the surface broadband albedo are obtained from a surface radiant flux observation net, such as FLUXNET [113], Baseline Surface Radiation Network (BSRN) [114], Surface Radiation budget network (SURFRAD) [115], and Greenland Climate Network (GC-NET) [116]. However, the most important issue is that the footprint of ground measurements and the satellite pixel are sometimes not comparable, thus requiring an up-scaling of ground-measured albedo with the aid of high-resolution albedo products [49]. In recent years, more and more studies [51,117] have evaluated the representativeness of ground stations with geostatistical attributes, and the data with high representativeness are screened for validating the generated surface albedo products.

\subsection{Gap Filling}

There are usually large data gaps in surface broadband albedo products derived from satellite data (for example, 20\%-40\% for the MCD43B3 albedo product) due to cloud coverage, seasonal snow cover and sensor malfunction [118]. As the spatial and temporal continuity is important for applications, the gap-filling algorithms are required for filling and filtering the missing data. In the current studies, there are mainly two strategies: pre-processing and post-processing. The pre-processing strategy is to improve the data quality of the input data for estimating surface albedo. Ju et al. [119] improved the input data quality with an adapted method based on the MODIS nadir BRDF adjusted reflectance (NBAR) data, and Samain et al. [120] fill the gaps in the time-series of BRDF coefficients with a Kalman filter. In the GlobAlbedo product, a regularization method was used to generate daily kernel coefficients [121]. In contrast, the post-processing strategy fills the gaps of the albedo products that have been derived. The main post-processing methods for filling the gaps of the albedo products are the ecosystem curving fitting (ECF), temporal spatial filter (TSF), and Statistics-based temporal filter (STF). The ECF method fills the missing data by pixel-level and regional albedo climatology curves and has been applied for generating a spatially complete albedo dataset based on the MOD43B3 products [122]. Fang et al. [123,124] proposed the TSF method for generating the gap-free albedo and leaf area index product based on the climatology 
of multi-year observations and neighboring observations. In the GLASS albedo products, the preliminary results are filtered by the STF method based on Bayesian theory for deriving the final products [101].

\subsection{Spatial and Temporal Resolutions}

The spatial and temporal resolution are major characters of surface albedo products. However, the spatial and temporal resolutions of current products are not adequate in some conditions. For example, when snow falls or melts, the land-surface albedo changes rapidly, which is not suitable to describe this process with weekly or monthly albedo products, and the daily surface albedo products are required [62]. In addition, the spatial resolution of surface albedo products is also important. When the land cover is heterogeneous (e.g., patchy agricultural/forestland, urban area), the products with 1-km resolution are not suitable for describing the spatial variation of albedo for this situation. Several studies focus on generating high spatial resolutions of the surface albedo products with a Landsat TM [125,126], Compact High Resolution Imaging Spectrometer (CHRIS)/PRoject for On Board Autonomy (PROBA) [127], HJ-1A/B [128], and AVIRIS [68], and the resolution-enhancing method [129] has also been studied for deriving surface broadband albedo products with finer spatial resolution.

\subsection{Ocean Albedo}

The broadband albedo over the ocean and sea-ice surfaces is important for the energy budget studies in the oceanic and polar regions. The ocean covers more than $70 \%$ of the Earth's surface, which plays an important role in the energy exchange and re-distribution due to its high specific heat capacity and the upper ocean redistributes heat through large-scale oceanic currents and atmospheric circulation [130]. In the high latitude regions, the surface of ocean water is usually covered with snow/sea-ice with high reflectance properties. The annual melts/freezes of the Arctic/Antarctic sea-ice result in large albedo changes in the polar region, which can significantly affect the global and regional climate [131,132].

The ocean albedo depends on the wind field, concentrations of chlorophyll, suspended particles, and colored dissolved organic matter (CDOM) in the ocean water, while the sea-ice albedo is closely related to the snow/sea-ice grain size, concentration of air bubbles, brine pocket, and contaminations in the sea ice, as well as the melt pond fraction $[133,134]$. The ocean surface albedo can be separated into three components: water leaving reflectance, sun glint, and whitecaps [135]. In the climate model, the ocean surface is modeled as flat surface [136] or declining facets [137] and calculated with Snell's law, the Fresnel formulae, and the Cox and Munk function [138]. However, the albedo contributions of the water leaving reflectance and whitecaps are not considered in these studies. In most regional and global climate models, simple schemes are used for describing sea-ice albedo, which only take into consideration the relationship between snow age and surface temperature [139].

Although many surface broadband albedo products over the land-surfaces have been generated, few products contain albedo over the ocean and sea-ice surfaces. It is also notable that the current products only contain albedo over the land-surfaces and that the albedo over the ocean and sea-ice surface is usually left blank. This is because the BRDF model for ocean water and sea-ice is quite different from that of land surfaces and the temporal dynamics are much more dramatic than the snow-free land surfaces. The only available surface broadband albedo products are the CLARA SAL product [94] and the GLASS phase-2 surface albedo product. In the CLARA surface albedo product, the albedo over the sea-ice 
surface is derived based on a temporal average method based on the lambertian assumption, and the albedo over the ocean surface is derived based on a look-up table proposed by Jin et al. [140]. In the GLASS phase- 2 surface albedo product, the albedo over the Arctic sea-ice surface will be derived from a direct-estimation algorithm based on a prior BRDF database that is generated by model simulations [141], and the albedo over the ocean surface will be generated by a three-component ocean water albedo (TCOWA) model and reanalysis data [142].

\subsection{Discussion of Products}

Although encouraging achievements have been acquired, the current surface broadband albedo products still suffer from the problems of product accuracy, temporal resolution, and data integrity [143]. The regions with large uncertainty and low confidence in product accuracy are high latitude snow/ice [107,108], desert [65], and mountain area [144]. In addition, the methods for collaborating multi-source satellite observations, data pre-processing, and gap filling also need to be further improved in future studies. Therefore, the methods to estimate the measurement uncertainties and differences in multi-radiometer characteristics are necessary [80].

The long-term record data are particularly important for climate change studies, and the temporal span of the current surface albedo products is still relatively short for such research purposes [145]. In addition, when the reflectance properties of the Earth's surfaces change rapidly (for example, snow fall and melt, deforest, and harvest) in the patchy regions, finer spatial and temporal surface albedo products are required.

The requirement of the accuracy and the temporal and spatial resolution of the surface broadband albedo product mainly depend on the specific applications and regional spatial-temporal heterogeneity. Therefore, current products still need to be improved to meet the requirements of different regional/global applications. Meanwhile, a more accurate albedo product is required for providing a better assessment of the albedo climatology, trends, and anthropogenic impacts, such as land cover and land use change, which is important for both researchers and policymakers [103]. Long-term, global fully covered (including land, ocean, and sea-ice surfaces), gap-free, surface broadband albedo products with higher spatial and temporal resolution are required by the global climate change, surface energy budget and regional hydrological studies.

\section{Conclusions}

In this paper, we present a comprehensive review of algorithms and products for mapping surface broadband albedo from satellite observations. The salient points are summarized as follows:

(1) A literature analysis for mapping surface broadband albedo is carried out with the HistCite software. From this analysis, we can conclude that the observation technologies and accuracy requirement of applications are sources of innovations. The studies have changed significantly with the developments of observation technologies, from ground/airborne platforms to geostationary and polar-orbit satellites, as well as from single-angular to multi-angular observation platforms. The publications and citations peak years are closely related to the launch time of satellites. Meanwhile, the requirement of applications (e.g., regional hydrology, urban environment monitoring and global climate change 
assessments) is another driving force for deriving long-term, gap free albedo products with higher spatial and temporal resolutions.

(2) The narrow-to-broadband conversions, BRDF angular modeling, direct-estimation algorithm, and the algorithm for geostationary satellites are reviewed and discussed. These algorithms have advantages for different aspects. For example, although the AMBRALS BRDF/albedo algorithm is physically robust, the temporal resolution of the albedo product derived from it is relatively course [62]. Conversely, the direct-estimation algorithm enables the estimation of the surface broadband albedo with a single-angular observation, though the results show larger fluctuations than the results estimated by the AMBRALS algorithm [65]. Therefore, it is necessary to consider the data fusion of the estimation results derived from different algorithms. In addition, the algorithms that collaborate multi-source observations are a promising solution for improving the accuracy and robustness of the surface broadband albedo.

(3) The currently available surface broadband albedo products from satellite observations are listed, and the issues for validation, gap filling, spatial/temporal resolution, ocean albedo, and challenges are presented in this paper. As a variety of surface albedo products have been generated, it is a challenged issue to estimate run-time uncertainty of different albedo products. It can be concluded that the long-term, global fully covered (including land, ocean, and sea-ice surfaces), gap-free, surface broadband albedo products with higher spatial and temporal resolution are required for climate change, regional energy budget and hydrological studies.

\section{Acknowledgments}

This study has been financially supported by the China Postdoctoral Science Foundation (2014M550025), the Chinese Natural Science Foundation Project (41371356), the "State Program for High-Tech Research and Development (863 program)" (2013AA122801), the Chinese Natural Science Foundation Project (41331173), and the International S\&T Cooperation Program of China (2012DFG21710). The authors would like to thank the anonymous reviewers for their valuable comments and suggestions.

\section{Author Contributions}

Ying Qu wrote the first draft of this review. Shunlin Liang, Qiang Liu, Tao He, Suhong Liu and Xiaowen Li reviewed and provided valuable comments for revising the original manuscript. All the authors agreed to be listed, and accepted this version for publication.

\section{Conflicts of Interest}

The authors declare no conflict of interest.

\section{Appendix}

\section{Appendix 1. Fundamental Principle, Nomenclatures and Symbols of the BRDF and Albedo}

In most of the circumstances of illumination, the natural and artificial objects on the Earth are neither ideal specular (mirror-like) nor ideal diffuse reflectors (Lambertian). The directional reflectance over 
land/ocean surfaces varies with the viewing and illuminating directions. Therefore, the Bidirectional Reflectance Distribution Function (BRDF) is widely used for describing the reflectance anisotropic property, which was defined by Nicodemus et al. (1977) [146] (Figure A1),

$$
\mathrm{BRDF}_{\lambda}=f_{\lambda}\left(\theta_{s}, \varphi_{s} ; \theta_{v}, \varphi_{v}\right)=\frac{d L_{\lambda}\left(\mathbf{\Omega}_{\mathrm{s}}, \mathbf{\Omega}_{\mathrm{v}}\right)}{d E_{\lambda}\left(\mathbf{\Omega}_{\mathrm{s}}\right)}=\frac{d L_{\lambda}\left(\theta_{s}, \varphi_{s} ; \theta_{v}, \varphi_{v}\right)}{d E_{\lambda}\left(\theta_{s}, \varphi_{s}\right)}\left[s r^{-1}\right]
$$

where $\left(\boldsymbol{\Omega}_{s}, \boldsymbol{\Omega}_{v}\right)$ stands for the incident and viewing directions, which can also be expressed in the form of a zenith angle $(\theta)$ and azimuth angle $(\varphi)$ : the irradiance direction is $\left(\theta_{S}, \varphi_{S}\right)$ and the viewing direction is $\left(\theta_{\mathrm{v}}, \varphi_{v}\right)$, respectively. $d E_{\lambda}\left(\boldsymbol{\Omega}_{s}\right)$ is the increment of spectral irradiance $\left(\mathrm{Wm}^{-2} \mu m^{-1}\right)$ in an incoming beam $\left(\boldsymbol{\Omega}_{S}\right)$ on a given point of a surface or plane at wavelength $\lambda$, while $d L_{\lambda}\left(\boldsymbol{\Omega}_{s}, \boldsymbol{\Omega}_{v}\right)$ is the increment of the corresponding reflected spectral radiance $\left(\mathrm{Wm}^{-2} s r^{-1} \mu m^{-1}\right)$ from the point in the sensor viewing direction $\left(\boldsymbol{\Omega}_{v}\right)$.

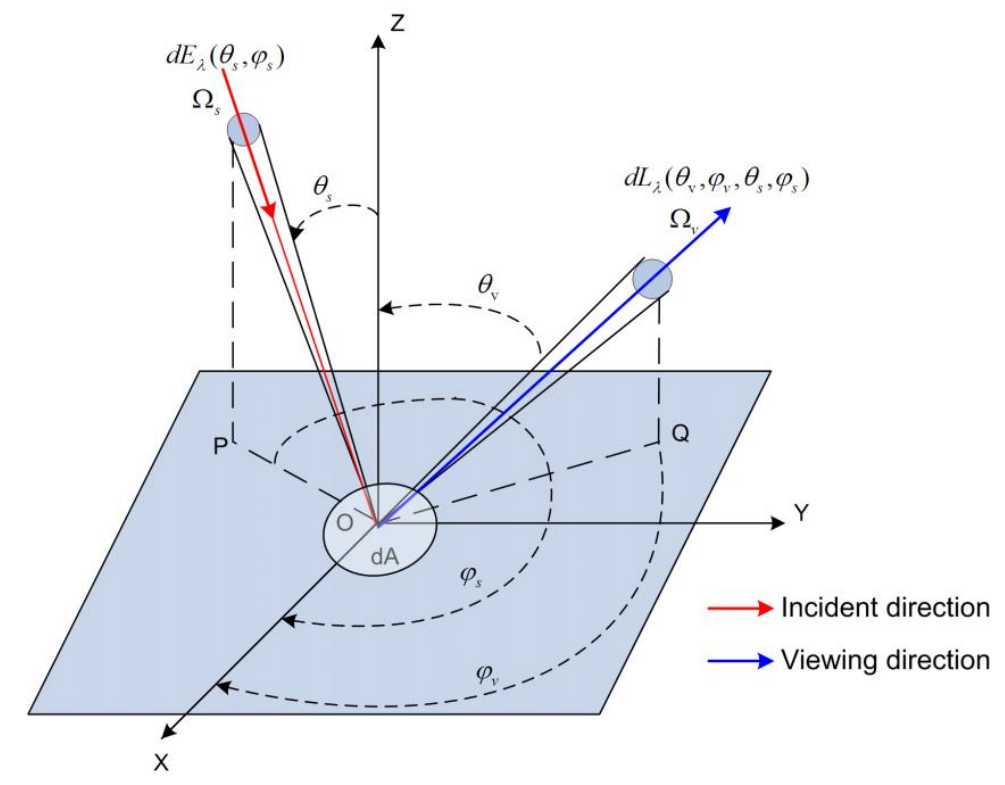

Figure A1. Incident and viewing geometries for definition of BRDF.

However, the BRDF cannot be practically and rigorously measured in natural illumination circumstances; thus, the Bidirectional Reflectance Factor (BRF) is usually used instead, which is defined by the ratio of the reflected radiant flux from the target surface to the counterpart from an ideal diffuse surface within the same area under an identical solar/view geometry. When the view solid angle approaches 0, the BRF can be expressed as a simple mathematical function of the BRDF [147],

$$
\alpha_{b s}\left(\mathbf{\Omega}_{\mathrm{s}}\right)=\frac{1}{\pi} \int_{0}^{2 \pi} \int_{0}^{1} R\left(\boldsymbol{\Omega}_{\mathrm{s}}, \mathbf{\Omega}_{\mathbf{v}}\right) \mu_{v} d \mu_{v} d \varphi_{v}
$$

where $R_{\lambda}\left(\boldsymbol{\Omega}_{s}, \boldsymbol{\Omega}_{v}\right)$ denotes the BRF, which is a function of the wavelength $\lambda$. In the following sections, the wavelength symbol is omitted, which makes the following equations much clearer and easier to read.

The surface albedo is defined as the ratio of upward and downward radiation flux, where the downward radiation flux can be categorized into two parts: directional and diffuse radiation. When the surface is illuminated with ideal directional radiation, the surface albedo is called black-sky albedo (BSA) or directional-hemispherical reflectance (DHR), which can be expressed as the integration of its BRF over the incident semi-hemisphere, 


$$
\alpha_{b s}\left(\mathbf{\Omega}_{\mathrm{s}}\right)=\frac{1}{\pi} \int_{0}^{2 \pi} \int_{0}^{1} R\left(\mathbf{\Omega}_{\mathbf{s}}, \mathbf{\Omega}_{\mathbf{v}}\right) \mu_{v} d \mu_{v} d \varphi_{v}
$$

where $\alpha\left(\boldsymbol{\Omega}_{s}\right)$ is the black-sky albedo in the illuminating direction $\boldsymbol{\Omega}_{s}, R_{\lambda}\left(\boldsymbol{\Omega}_{s}, \boldsymbol{\Omega}_{v}\right)$ is the BRF of the surface, and $\mu_{v}=\cos \theta_{v}$.

When the surface is illuminated with ideal diffuse radiation, the surface albedo is called white-sky albedo (WSA) or bi-hemispherical reflectance (BHR), which can be expressed as a double integration over the illuminating and viewing semi-hemisphere,

$$
\alpha_{w s}=\frac{1}{\pi} \int_{0}^{2 \pi} \int_{0}^{1} \alpha\left(\boldsymbol{\Omega}_{\mathrm{s}}\right) \mu_{s} d \mu_{s} d \varphi_{s}=\frac{1}{\pi^{2}} \int_{0}^{2 \pi} \int_{0}^{1} \int_{0}^{2 \pi} \int_{0}^{1} R\left(\boldsymbol{\Omega}_{\mathrm{s}}, \boldsymbol{\Omega}_{\mathrm{v}}\right) \mu_{v} d \mu_{v} d \varphi_{v} \mu_{s} d \mu_{s} d \varphi_{s}
$$

where $\alpha_{w s}$ is the white-sky albedo and $\mu_{s}=\cos \theta_{s}$. Figure A2 shows the flowchart for deriving the black and white-sky albedo from BRDF.

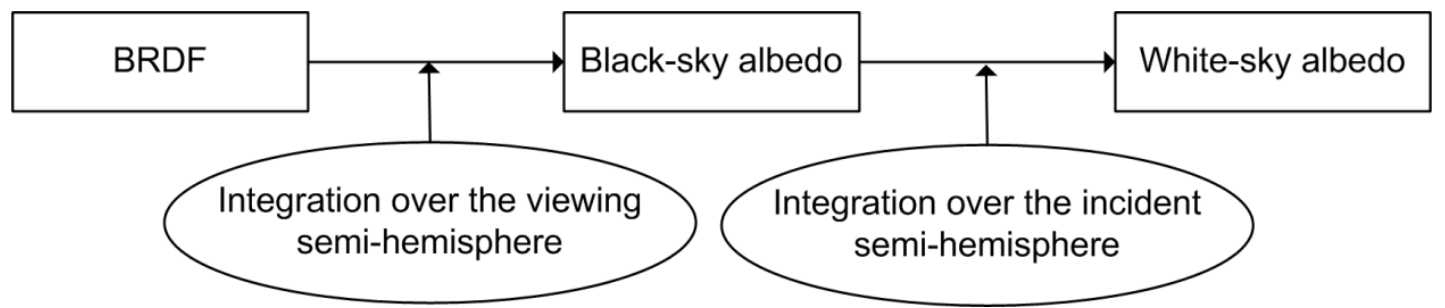

Figure A2. Flow chart of deriving the black and white-sky albedo from BRDF.

The instantaneous surface albedo measured under natural daylight illumination is usually called blue-sky albedo and can be approximately expressed as a linear combination of black and white-sky albedo [106,148,149].

$$
\alpha\left(\mathbf{\Omega}_{\mathrm{s}}\right) \approx(1-D(\tau, \lambda)) \alpha_{b s}\left(\mathbf{\Omega}_{\mathrm{s}}\right)+D(\tau, \lambda) \alpha_{w s}
$$

where $\mathrm{D}(\tau, \lambda)$ denotes the fraction of diffuse light, which varies with the aerosol optical wavelength (AOD) $\tau$ and wavelength $\lambda$.

The surface broadband albedo can be estimated by the integration of the spectral albedo (narrowband albedo) weighted by the distribution of the incident radiation flux varied with wavelengths [47],

$$
\alpha\left(\theta_{s}\right)=\frac{\int_{\lambda_{1}}^{\lambda_{2}} F_{d}\left(\theta_{s}, \lambda\right) \alpha_{\lambda}\left(\theta_{s}\right) d \lambda}{\int_{\lambda_{1}}^{\lambda_{2}} F_{d}\left(\theta_{s}, \lambda\right) d \lambda}
$$

where $\alpha\left(\theta_{s}\right)$ is the broadband albedo, $\alpha_{\lambda}\left(\theta_{s}\right)$ is the narrowband albedo, and $F_{d}\left(\theta_{s}, \lambda\right)$ is the downward solar radiation flux.

According to the above physical definitions, the surface albedo can be estimated by integrations over atmospheric corrected, cloud-free, multi-angular satellite observations. However, it is hard to observe an object on Earth in all solar/view angles simultaneously on a global scale, so it is important to build a BRDF model for describing the surface anisotropy, which can be used for interpolating and extrapolating the BRF in the solar/view angles without satellite observations. In the earlier studies, the BRF is usually fitted by empirical functions [2], such as Minnaert [150], Shibayama and Wiegand [151], Walthall [152] and Staylor-Suttles [153]. In the current studies, the BRF is usually fitted with a semi-empirical linear 
kernel-driven model, which expresses the BRF as a linear combination of isotropic, volume scattering and geometrical optical kernels,

$$
R_{\Lambda}\left(\mathbf{\Omega}_{\mathrm{s}}, \mathbf{\Omega}_{\mathbf{v}}\right)=f_{i s o, \Lambda}+f_{v o l, \Lambda} K_{v o l}\left(\mathbf{\Omega}_{\mathrm{s}}, \mathbf{\Omega}_{\mathbf{v}}\right)+f_{g e o, \Lambda} K_{g e o}\left(\mathbf{\Omega}_{\mathrm{s}}, \mathbf{\Omega}_{\mathbf{v}}\right)
$$

where $K_{v o l}$ and $K_{g e o}$ are the volume scattering, and geometrical optical kernel functions, and $f_{i s o}, f_{v o l}$, and $f_{g e o}$ are the isotropic, volume scattering and geometric optical kernel coefficients, respectively. The symbol $\Lambda$ denotes the band of satellite sensors.

The coefficients of the linear kernel-driven model can be calculated by a least square regression with atmospheric corrected multi-angular reflectance data, where the black and white-sky albedo can be calculated as $[42,46]$,

$$
\begin{gathered}
\alpha_{b s}\left(\theta_{s}\right)=\sum_{k} f_{k} h_{k}\left(\theta_{s}\right) \\
\alpha_{w s}=\sum_{k} f_{k} H_{k}
\end{gathered}
$$

where $h_{k}\left(\theta_{s}\right)$ is the integration of kernel function $K_{k}\left(\boldsymbol{\Omega}_{s}, \boldsymbol{\Omega}_{v}\right), K_{k}$ is the integration of $h_{k}\left(\theta_{s}\right)$ over the incident semi-hemisphere, which can be fitted by as follows,

$$
h_{k}\left(\theta_{s}\right)=g_{0 k}+g_{1 k} \theta_{s}^{2}+g_{2 k} \theta_{s}^{3}
$$

According to Equations (9) and (10), the black and white-sky albedo can be estimated by [59,154],

$$
\begin{array}{r}
\alpha_{b s}\left(\theta_{s}, \lambda\right)=f_{\text {iso }}(\lambda)\left(g_{0 i s o}+g_{1 i s o} \theta_{s}^{2}+g_{2 i s o} \theta_{s}^{3}\right)+ \\
f_{v o l}(\lambda)\left(g_{0 v o l}+g_{1 v o l} \theta_{s}^{2}+g_{2 v o l} \theta_{s}^{3}\right)+ \\
f_{g e o}(\lambda)\left(g_{0 \text { geo }}+g_{1 g e o} \theta_{s}^{2}+g_{2 g e o} \theta_{s}^{3}\right) \\
\alpha_{w s}(\lambda)=f_{\text {iso }}(\lambda) g_{\text {iso }}+f_{\text {vol }}(\lambda) g_{\text {vol }}+f_{\text {geo }}(\lambda) g_{\text {geo }}
\end{array}
$$

where $g_{j k}$ and $g_{k}$ are the coefficients for calculating the black and white-sky albedo.

According to Equation (6), the surface broadband albedo can be estimated from narrowband albedo [47],

$$
\alpha=\sum_{n} c_{n} \alpha(\lambda)
$$

where $n$ is the band number of satellite sensors, $c_{n}$ is the narrow-to-broadband conversion coefficient of band $n$.

Recently, the direct-estimation algorithm is also used for estimating surface broadband albedo, which incorporates to estimate surface broadband albedo from a single-angular observation. The concept of the direct-estimation algorithm is to build a linear regression relationship between top of atmosphere (TOA) BRF and surface broadband albedo in different angular bins based on BRDF database, which can be expressed as follows [62],

$$
\begin{gathered}
\alpha_{w s}=m_{0}\left(\theta_{s}, \theta_{v}, \varphi\right)+\sum_{i=1}^{n} m_{i}\left(\theta_{s}, \theta_{v}, \varphi\right) \rho_{i}^{T O A}\left(\theta_{s}, \theta_{v}, \varphi\right) \\
\alpha_{b s}\left(\theta_{b s}\right)=n_{0}\left(\theta_{b s a}, \theta_{s}, \theta_{v}, \varphi\right)+\sum_{i=1}^{n} n_{i}\left(\theta_{b s a}, \theta_{s}, \theta_{v}, \varphi\right) \rho_{i}^{T O A}\left(\theta_{s}, \theta_{v}, \varphi\right)
\end{gathered}
$$


where $\rho_{i}^{T O A}\left(\theta_{s}, \theta_{v}, \varphi\right)$ is the TOA BRF of band $\mathrm{i}$ at solar zenith angle of $\theta_{s}$, view zenith angle of $\theta_{v}$ and relative azimuth angle of $\varphi ; m_{0}\left(\theta_{s}, \theta_{v}, \varphi\right)$ and $n_{0}\left(\theta_{b s a}, \theta_{s}, \theta_{v}, \varphi\right)$ are the intersection terms of the regression equation, $m_{i}\left(\theta_{s}, \theta_{v}, \varphi\right)$ and $n_{i}\left(\theta_{b s a}, \theta_{s}, \theta_{v}, \varphi\right)$ are the coefficients of the regression equation for each corresponding angular bin.

In this section, we introduce the fundamental principle of the surface broadband albedo, and the nomenclatures and symbols are according to the definition of Schaepman-Strub et al. [155] and algorithm theoretical base document (ATBD) of the MODIS BRDF/albedo product [156].

\section{References}

1. Dickinson, R.E. Land surface processes and climate-Surface albedos and energy balance. Adv. Geophys. 1983, 25, 305-353.

2. Liang, S. Quantitative Remote Sensing of Land Surfaces; Wiley: New York, NY, USA, 2004.

3. Liang, S.; Wang, K.; Zhang, X.; Wild, M. Review on estimation of land surface radiation and energy budgets from ground measurement, remote sensing and model simulations. IEEE J. Spec. Top. Appl. Earth Obs. Remote Sens. 2010, 3, 225-240.

4. Porter, D.F.; Cassano, J.J.; Serreze, M.C.; Kindig, D.N. New estimates of the large-scale Arctic atmospheric energy budget. J. Geophys. Res. 2010, 115, doi:10.1029/2009JD012653.

5. Trenberth, K.E.; Fasullo, J.T.; Kiehl, J. Earth's global energy budget. Bull. Am. Meteorol. Soc. 2009, 90, 311-323.

6. Sagan, C.; Toon, O.B.; Pollack, J.B. Anthropogenic albedo changes and the earth's climate. Science 1979, 206, 1363-1368.

7. Bala, G.; Caldeira, K.; Wickett, M.; Phillips, T.; Lobell, D.; Delire, C.; Mirin, A. Combined climate and carbon-cycle effects of large-scale deforestation. In Proceedings of the National Academy of Sciences, Stanford, CA, 24 February 2007.

8. Zhang, Y.; Liang, S. Surface radiative forcing of forest disturbances over Northeastern China. Environ. Res. Lett. 2014, 9, doi:10.1088/1748-9326/9/2/024002.

9. Charney, J.G. Dynamics of deserts and drought in the Sahel. Q. J. Roy. Meteorol. Soc. 2006, 101, 193-202.

10. Myhre, G.; Govaerts, Y.; Haywood, J.M.; Berntsen, T.K.; Lattanzio, A. Radiative effect of surface albedo change from biomass burning. Geophys. Res. Lett. 2005, 32, doi:20810.21029/22005GL022897.

11. He, T.; Liang, S.; Yu, Y.; Wang, D.; Gao, F.; Liu, Q. Greenland surface albedo changes 1981-2012 from satellite observations. Environ. Res. Lett. 2013, 8, doi:10.1088/1748-9326/8/4/044043.

12. Meier, W.N.; Stroeve, J.; Fetterer, F. Whither arctic sea ice? A clear signal of decline regionally, seasonally and extending beyond the satellite record. Ann. Glaciol. 2007, 46, 428-434.

13. Shi, Q.; Liang, S. Characterizing the surface radiation budget over the Tibetan Plateau with ground-measured, reanalysis, and remote sensing data sets: 2. Spatiotemporal analysis. J. Geophys. Res. Atmos. 2013, 118, 8921-8934.

14. Ramaswamy, V.; Boucher, O.; Haigh, J.; Hauglustine, D.; Haywood, J.; Myhre, G.; Nakajima, T.; Shi, G.; Solomon, S. Radiative Forcing of Climate. Available online: http://www.esrl.noaa.gov/ csd/assessments/ozone/1991/chapters/chapter7.pdf (accessed on 8 October 2014). 
15. Charney, J.; Stone, P.; Quirk, W. Drought in the Sahara: A biogeophysical feedback mechanism. Science 1975, 187, 434-435.

16. Courel, M.-F.; Kandel, R.; Rasool, S. Surface albedo and the Sahel drought. Nature 1984, 307, $528-531$.

17. Zeng, N.; Yoon, J. Expansion of the world's deserts due to vegetation-albedo feedback under global warming. Geophys. Res. Lett. 2009, 36, doi: 10.1029/2009GL039699.

18. Loew, A. Terrestrial satellite records for climate studies: How long is long enough? A test case for the Sahel. Theor. Appl. Climatol. 2014, 115, 427-440.

19. Curry, J.A.; Schramm, J.L.; Ebert, E.E. Sea ice-albedo climate feedback mechanism. J. Clim. 1995, 8, 240-247.

20. Déry, S.J.; Brown, R.D. Recent northern hemisphere snow cover extent trends and implications for the snow-albedo feedback. Geophys. Res. Lett. 2007, 34, doi:10.1029/2007GL031474.

21. Henderson-Sellers, A.; Wilson, M. Surface albedo data for climatic modeling. Rev. Geophys. 1983, $21,1743-1778$.

22. Wang, Z.; Zeng, X.; Barlage, M.; Dickinson, R.; Gao, F.; Schaaf, C. Using MODIS BRDF and albedo data to evaluate global model land surface albedo. J. Hydrometeorol. 2004, 5, 3-14.

23. Zhou, L.; Dickinson, R.; Tian, Y.; Zeng, X.; Dai, Y.; Yang, Z.-L.; Schaaf, C.; Gao, F.; Jin, Y.; Strahler, A. Comparison of seasonal and spatial variations of albedos From Moderate-Resolution Imaging Spectroradiometer (MODIS) and common land model. J. Geophys. Res. 2003, 108, doi:10.1029/2002JD003326.

24. Zhang, X.; Liang, S.; Wang, K.; Li, L.; Gui, S. Analysis of global land surface shortwave broadband albedo from multiple data sources. IEEE J. Sel. Top. Appl. Earth Obs. Remote Sens. 2010, 3, 296-305.

25. Boisier, J.; de Noblet-Ducoudré, N.; Ciais, P. Inferring past land use-induced changes in surface albedo from satellite observations: A useful tool to evaluate model simulations. Biogeosciences 2013, 10, 1501-1516.

26. Myhre, G.; Kvalevåg, M.M.; Schaaf, C.B. Radiative forcing due to anthropogenic vegetation change based on MODIS surface albedo data. Geophys. Res. Lett. 2005, 32, doi:10.1029/2005GL024004.

27. Jacob, F.; Olioso, A. Derivation of diurnal courses of albedo and reflected solar irradiance from airborne POLDER data acquired near solar noon. J. Geophys. Res. 2005, 110, doi:10.1029/2004JD004888.

28. Sellers, P.; Meeson, B.; Hall, F.; Asrar, G.; Murphy, R.; Schiffer, R.; Bretherton, F.; Dickinson, R.; Ellingson, R.; Field, C. Remote sensing of the land surface for studies of global change: Models_Algorithms-Experiments. Remote Sens. Environ. 1995, 51, 3-26.

29. Kriebel, K.T. Albedo of vegetated surfaces-Its variability with differing irradiances. Remote Sens. Environ. 1979, 8, 283-290.

30. Kimes, D.S.; Deering, D.W. Remote-sensing of surface hemispherical reflectance (albedo) using pointable multispectral imaging spectroradiometers. Remote Sens. Environ. 1992, 39, 85-94.

31. Irons, J.R.; Ranson, K.J.; Daughtry, C.S.T. Estimating big bluestem albedo from directional reflectance measurements. Remote Sens. Environ. 1988, 25, 185-199. 
32. Ranson, K.J.; Irons, J.R.; Daughtry, C.S.T. Surface albedo from bidirectional reflectance. Remote Sens. Environ. 1991, 35, 201-211.

33. Starks, P.J.; Norman, J.M.; Blad, B.L.; Waltershea, E.A.; Walthall, C.L. Estimation of shortwave hemispherical reflectance (albedo) from bidirectionally reflected radiance data. Remote Sens. Environ. 1991, 38, 123-134.

34. Brest, C.; Goward, S. Deriving surface albedo measurements from narrow band satellite data. Int. J. Remote Sens. 1987, 8, 351-367.

35. Russell, M.J.; Nunez, M.; Chladil, M.A.; Valiente, J.A.; LopezBaeza, E. Conversion of nadir, narrowband reflectance in red and near-infrared channels to hemispherical surface albedo. Remote Sens. Environ. 1997, 61, 16-23.

36. Saunders, R.W. The determination of broad band surface albedo from AVHRR visible and near-infrared radiances. Int. J. Remote Sens. 1990, 11, 49-67.

37. Duguay, C.R.; Ledrew, E.F. Estimating surface reflectance and albedo from Landsat-5 thematic mapper over rugged terrain. Photogramm. Eng. Remote Sens. 1992, 58, 551-558.

38. Knap, W.H.; Brock, B.W.; Oerlemans, J.; Willis, I.C. Comparison of Landsat TM-derived and ground-based albedos of Haut Glacier D'arolla, Switzerland. Int. J. Remote Sens. 1999, 20, 3293-3310.

39. Valiente, J.A.; Nunez, M.; Lopezbaeza, E.; Moreno, J.F. Narrow-band to broad-band conversion for Meteosat-visiible channel and broad-band albedo using both AVHRR-1 and-2 channels. Int. J. Remote Sens. 1995, 16, 1147-1166.

40. Stroeve, J.; Nolin, A.; Steffen, K. Comparison of AVHRR-derived and in situ surface albedo over the Greenland ice sheet. Remote Sens. Environ. 1997, 62, 262-276.

41. Minnis, P.; Mayor, S.; Smith, W.L.; Young, D.F. Asymmetry in the diurnal variation of surface albedo. IEEE Trans. Geosci. Remote Sens. 1997, 35, 879-891.

42. Lucht, W.; Schaaf, C.; Strahler, A. An algorithm for the retrieval of albedo from space using semiempirical BRDF models. IEEE Trans. Geosci. Remote Sens. 2000, 38, 977-998.

43. Barnsley, M.J.; Hobson, P.D.; Hyman, A.H.; Lucht, W.; Muller, J.P.; Strahler, A.H. Characterizing the spatial variability of broadband albedo in a semidesert environment for MODIS validation. Remote Sens. Environ. 2000, 74, 58-68.

44. Lucht, W.; Hyman, A.H.; Strahler, A.H.; Barnsley, M.J.; Hobson, P.; Muller, J.P. A comparison of satellite-derived spectral albedos to ground-based broadband albedo measurements modeled to satellite spatial scale for a semidesert landscape. Remote Sens. Environ. 2000, 74, 85-98.

45. Lucht, W.; Lewis, P. Theoretical noise sensitivity of BRDF and albedo retrieval from the EOS-MODIS and MISR sensors with respect to angular sampling. Int. J. Remote Sens. 2000, 21, 81-98.

46. Schaaf, C.; Gao, F.; Strahler, A.; Lucht, W.; Li, X.; Tsang, T.; Strugnell, N.; Zhang, X.; Jin, Y.; Muller, J. First operational BRDF, albedo nadir reflectance products from MODIS. Remote Sens. Environ. 2002, 83, 135-148.

47. Liang, S. Narrowband to broadband conversions of land surface albedo I: Algorithms. Remote Sens. Environ. 2001, 76, 213-238.

48. Ricchiazzi, P.; Yang, S.; Gautier, C.; Sowle, D. SBDART: A research and teaching software tool for plane parallel radiative transfer in the earth's atmosphere. Bull. Am. Meteorol. Soc. 1998, 79, 2101-2114. 
49. Liang, S.; Fang, H.; Chen, M.; Shuey, C.; Walthall, C.; Daughtry, C.; Morisette, J.; Schaaf, C.; Strahler, A. Validating MODIS land surface reflectance and albedo products: Methods and preliminary results. Remote Sens. Environ. 2002, 83, 149-162.

50. Liang, S.; Shuey, C.; Russ, A.; Fang, H.; Chen, M.; Walthall, C.; Daughtry, C.; Hunt, R. Narrowband to broadband conversions of land surface albedo: II. Validation. Remote Sens. Environ. 2003, 84, 25-41.

51. Roman, M.O.; Schaaf, C.B.; Woodcock, C.E.; Strahler, A.H.; Yang, X.Y.; Braswell, R.H.; Curtis, P.S.; Davis, K.J.; Dragoni, D.; Goulden, M.L.; et al. The MODIS (collection v005) BRDF/albedo product: Assessment of spatial representativeness over forested landscapes. Remote Sens. Environ. 2009, 113, 2476-2498.

52. Stroeve, J.; Box, J.; Gao, F.; Liang, S.; Nolin, A.; Schaaf, C. Accuracy assessment of the MODIS 16-day albedo product for snow: Comparisons with Greenland in situ measurements. Remote Sens. Environ. 2005, 94, 46-60.

53. Susaki, J.; Yasuoka, Y.; Kajiwara, K.; Honda, Y.; Hara, K. Validation of MODIS albedo products of paddy fields in Japan. IEEE Trans. Geosci. Remote Sens. 2007, 45, 206-217.

54. Klein, A.G.; Stroeve, J. Development and validation of a snow albedo algorithm for the MODIS instrument. Ann. Glaciol. 2002, 34, 45-52.

55. Liang, S. A direct algorithm for estimating land surface broadband albedos from MODIS imagery. IEEE Trans. Geosci. Remote Sens. 2003, 41, 136-145.

56. Liang, S.; Yu, Y.; Defelice, T.P. VIIRS narrowband to broadband land surface albedo conversion: Formula and validation. Int. J. Remote Sens. 2005, 26, 1019-1025.

57. Xiong, X.; Stamnes, K.; Lubin, D. Surface albedo over the arctic ocean derived from AVHRR and its validation with SHEBA data. J. Appl. Meteorol. 2002, 41, 413-425.

58. Maignan, F.; Bréon, F.; Lacaze, R. Bidirectional reflectance of earth targets: Evaluation of analytical models using a large set of spaceborne measurements with emphasis on the hot spot. Remote Sens. Environ. 2004, 90, 210-220.

59. Roujean, J.L.; Leroy, M.; Deschamps, P.Y. A bidirectional reflectance model of the earth's surface for the correction of remote sensing data. J. Geophys. Res. 1992, 97, 20455-20468.

60. Wang, Z.; Schaaf, C.B.; Chopping, M.J.; Strahler, A.H.; Wang, J.; Román, M.O.; Rocha, A.V.; Woodcock, C.E.; Shuai, Y. Evaluation of Moderate-Resolution Imaging Spectroradiometer (MODIS) snow albedo product (MCD43A) over tundra. Remote Sens. Environ. 2012, 117, 264-280.

61. Wang, Z.; Schaaf, C.B.; Strahler, A.H.; Chopping, M.J.; Román, M.O.; Shuai, Y.; Woodcock, C.E.; Hollinger, D.Y.; Fitzjarrald, D.R. Evaluation of MODIS albedo product (MCD43A) over grassland, agriculture and forest surface types during dormant and snow-covered periods. Remote Sens. Environ. 2014, 140, 60-77.

62. Qu, Y.; Liu, Q.; Liang, S.; Wang, L.; Liu, N.; Liu, S. Direct-estimation algorithm for mapping daily land-surface broadband albedo from MODIS data. IEEE Trans. Geosci. Remote Sens. 2014, 52, 907-919.

63. Liang, S.; Strahler, A.; Walthall, C. Retrieval of land surface albedo from satellite observations: A simulation study. J. Appl. Meteorol. 1999, 38, 712-725.

64. Liang, S.; Stroeve, J.; Box, J. Mapping daily snow/ice shortwave broadband albedo from Moderate Resolution Imaging Spectroradiometer (MODIS): The improved direct retrieval algorithm and 
validation with greenland in situ measurement. J. Geophys. Res. 2005, 110, doi: 10.1029/2004JD005493.

65. Wang, D.; Liang, S.; He, T.; Yu, Y. Direct estimation of land surface albedo from VIIRS data: Algorithm improvement and preliminary validation. J. Geophys. Res. Atmos. 2013, 118, 12577-12586.

66. Cui, Y.; Mitomi, Y.; Takamura, T. An empirical anisotropy correction model for estimating land surface albedo for radiation budget studies. Remote Sens. Environ. 2009, 113, 24-39.

67. Liang, S.L.; Fang, H.L.; Kaul, M.; Van Niel, T.G.; McVicar, T.R.; Pearlman, J.S.; Walthall, C.L.; Daughtry, C.S.T.; Huemmrich, K.F. Estimation and validation of land surface broadband albedos and leaf area index from EO-1 ALI data. IEEE Trans. Geosci. Remote Sens. 2003, 41, 1260-1267.

68. He, T.; Liang, S.; Wang, D.; Shi, Q.; Tao, X. Estimation of high-resolution land surface shortwave albedo from AVIRIS data. IEEE J. Sel. Top. Appl. Earth Obs. Remote Sens. 2014, in press.

69. Rahman, H.; Verstraete, M.; Pinty, B. Coupled Surface-Atmosphere Reflectance (CSAR) model: 1. Model description and inversion on synthetic data. J. Geophys. Res. 1993, 98, 20779-20801.

70. Lattanzio, A.; Schulz, J.; Matthews, J.; Okuyama, A.; Theodore, B.; John, J.B.; Knapp, K.R.; Kosaka, Y.; Schuller, L. Land surface albedo from geostationary satellites: A multiagency collaboration within SCOPE-CM. Bull. Am. Meteorol. Soc. 2013, 94, 205-214.

71. Lattanzio, A.; Govaerts, Y.M.; Pinty, B. Consistency of surface anisotropy characterization with Meteosat observations. Adv. Space Res. 2007, 2007, 131-135.

72. Knapp, K.R.; Frouin, R.; Kondragunta, S.; Prados, A. Toward aerosol optical depth retrievals over land from GOES visible radiances: Determining surface reflectance. Int. J. Remote Sens. 2005, 26, 4097-4116.

73. Popp, C.; Hauser, A.; Foppa, N.; Wunderle, S. Remote sensing of aerosol optical depth over central Europe from MSG-SEVIRI data and accuracy assessment with ground-based AERONET measurements. J. Geophys. Res. Atmos. 2007, 112, doi:10.1029/2007JD008423.

74. Geiger, B.; Carrer, D.; Franchisteguy, L.; Roujean, J.L.; Meurey, C. Land surface albedo derived on a daily basis from Meteosat second generation observations. IEEE Trans. Geosci. Remote Sens. 2008, 46, 3841-3856.

75. Govaerts, Y.M.; Wagner, S.; Lattanzio, A.; Watts, P. Joint retrieval of surface reflectance and aerosol optical depth from MSG/SEVIRI observations with an optimal estimation approach: 1. Theory. J. Geophys. Res. Atmos. 2010, 115, doi:10.1029/2009JD011779.

76. Pinty, B.; Roveda, F.; Verstraete, M.; Gobron, N.; Govaerts, Y.; Martonchik, J.; Diner, D.; Kahn, R. Surface albedo retrieval from Meteosat: 1. Theory. J. Geophys. Res. 2000, 105, 18099-18112.

77. Mei, L.; Xue, Y.; de Leeuw, G.; Holzer-Popp, T.; Guang, J.; Li, Y.; Yang, L.; Xu, H.; Xu, X.; Li, C.; et al. Retrieval of aerosol optical depth over land based on a time series technique using MSG/SEVIRI data. Atmos. Chem. Phys. 2012, 12, 9167-9185.

78. Govaerts, Y.M.; Lattanzio, A.; Pinty, B.; Schmetz, J. Consistent surface albedo retrieval from two adjacent geostationary satellites. Geophys. Res. Lett. 2004, 31, doi:10.1029/2004GL020418.

79. Govaerts, Y.; Lattanzio, A.; Taberner, M.; Pinty, B. Generating global surface albedo products from multiple geostationary satellites. Remote Sens. Environ. 2008, 112, 2804-2816.

80. Govaerts, Y.; Lattanzio, A. Retrieval error estimation of surface albedo derived from geostationary large band satellite observations: Application to Meteosat-2 and Meteosat-7 data. J. Geophys. Res. 2007, 112, doi:10.1029/2006JD007313. 
81. Schaaf, C.; Cihlar, J.; Belward, A.; Dutton, E. ECV T8: Albedo and Reflectance Anisotropy. Available online: http://159.226.251.229/videoplayer/GTOS-ECV-T08-albedo-v11.pdf? ich_u_r_i=ff71917ef4860cbb27684b38e8b66273\&ich_s_t_a_r_t=0\&ich_e_n_d=0\&ich_k_e_y=1 545018905750563122498\&ich_t_y_p_e=1\&ich_d_i_s_k_i_d=8\&ich_u_n_i_t=1 (accessed on 8 October 2014).

82. Gao, F.; Schaaf, C.; Strahler, A.; Roesch, A.; Lucht, W.; Dickinson, R. MODIS bidirectional reflectance distribution function and albedo climate modeling grid products and the variability of albedo for major global vegetation types. J. Geophys. Res. 2005, 110, doi: 10.1029/2004JD005190.

83. Martonchik, J.; Diner, D.; Kahn, R.; Ackerman, T.; Verstraete, M.; Pinty, B.; Gordon, H. Techniques for the retrieval of aerosol properties over land and ocean using multiangle imaging. IEEE Trans. Geosci. Remote Sens. 2002, 36, 1212-1227.

84. Martonchik, J.; Diner, D.; Pinty, B.; Verstraete, M.; Myneni, R.; Knyazikhin, Y.; Gordon, H. Determination of land and ocean reflective, radiative, and biophysical properties using multiangle imaging. IEEE Trans. Geosci. Remote Sens. 2002, 36, 1266-1281.

85. Martonchik, J.; Pinty, B.; Verstraete, M. Note on an improved model of surface BRDF-atmospheric coupled radiation. IEEE Trans. Geosci. Remote Sens. 2002, 40, 1637-1639.

86. Diner, D.J.; Martonchik, J.V.; Borel, C.; Gerstl, S.A.W.; Gordon, H.R.; Knyazikhin, Y.; Myneni, R.; Pinty, B.; Michel, V.M. Multi-Angle Imaging Spectro-Radiometer Level 2 Surface Retrieval Algorithm Theoretical Basis; Jet Propulsion Laboratory: La Cañada Flintridge, CA, USA, 2008.

87. Bacour, C.; Breon, F. Variability of biome reflectance directional signatures as seen by POLDER. Remote Sens. Environ. 2005, 98, 80-95.

88. Bicheron, P.; Leroy, M. Bidirectional reflectance distribution function signatures of major biomes observed from space. J. Geophys. Res. 2000, 105, 26669-26681.

89. Hautecœur, O.; Leroy, M. Surface bidirectional reflectance distribution function observed at global scale by POLDER/ADEOS. Geophys. Res. Lett. 1998, 25, 4197-4200.

90. Leroy, M.; Deuzé, J.; Bréon, F.; Hautecoeur, O.; Herman, M.; Buriez, J.; Tanré, D.; Bouffies, S.; Chazette, P.; Roujean, J. Retrieval of atmospheric properties and surface bidirectional reflectances over land from POLDER/ADEOS. J. Geophys. Res. 1997, 102, 17023-17037.

91. Muller, J. BRDF/Albedo Retrieval. Available online: http://www.brockmann-consult. de/albedomap/pdf/MERIS-AlbedoMap-ATBD_BRDF_Albedo-1.0.pdf (accessed on 8 October 2014).

92. Barnsley, M.; Quaife, T.; Hobson, P.; Shaw, J.; Lewis, P.; Disney, M.; Muller, J.; Strahler, A.; Barker-Schaaf, C.; Lucht, W. Estimation of land-surface albedo and biophysical properties using SPOT-4 VGT and semi-empirical BRDF models. In Proceedings of International SPOT4 Vegetation Conference, Stolkholm, Sweden, 25 April 2000.

93. Bréon, F.; Maignan, F.; Leroy, M.; Grant, I. Analysis of hot spot directional signatures measured from space. J. Geophys. Res. 2002, 107, 4282-4296.

94. Riihelä, A.; Manninen, T.; Laine, V.; Andersson, K.; Kaspar, F. CLARA-SAL: A global 28 yr timeseries of Earth's black-sky surface albedo. Atmos. Chem. Phys. 2013, 13, 3743-3762.

95. Govaerts, Y.M.; Pinty, B.; Taberner, M.; Lattanzio, A. Spectral conversion of surface albedo derived from Meteosat first generation observations. IEEE Geosci. Remote Sens. Lett. 2006, 3, $23-27$. 
96. Pinty, B.; Roveda, F.; Verstraete, M.; Gobron, N.; Govaerts, Y.; Martonchik, J.; Diner, D.; Kahn, R. Surface albedo retrieval from Meteosat: 2. Applications. J. Geophys. Res. 2000, 105, 18113-18134.

97. Loew, A.; Govaerts, Y. Towards multidecadal consistent Meteosat surface albedo time series. Remote Sens. 2010, 2, 957-967.

98. Geiger, B.; Roujean, J.; Carrer, D.; Meurey, C. The EUMETSAT Satellite Application Facility on Land Surface Analysis (LSA SAF). Available online: http://landsaf.meteo.pt/ GetDocument.do?id=465 (accessed on 8 October 2014).

99. Van Leeuwen, W.J.D.; Roujean, J.L. Land surface albedo from the synergistic use of polar (EPS) and geo-stationary (MSG) observing systems: An assessment of physical uncertainties. Remote Sens. Environ. 2002, 81, 273-289.

100. Muller, J.-P.; López, G.; Watson, G.; Shane, N.; Kennedy, T.; Yuen, P.; Lewis, P. The ESA Globalbedo Project for Mapping the Earth's Land Surface Albedo for 15 Years from European Sensors. Available online: http://www.mssl.ucl.ac.uk/ pcy/papers/Muller-GlobAlbedo-abstractV4.pdf (accessed on 8 October 2014).

101. Liu, Q.; Wang, L.; Qu, Y.; Liu, N.; Tang, H.; Liang, S.; Liu, S. Preliminary evaluation of the long-term glass albedo product. Int. J. Digit. Earth 2013, 6, 5-33.

102. Liang, S.; Zhao, X.; Yuan, W.; Liu, S.; Cheng, X.; Xiao, Z.; Zhang, X.; Liu, Q.; Cheng, J.; Tang, H.; et al. A long-term Global LAnd Surface Satellite (GLASS) dataset for environmental studies. Int. J. Digit. Earth 2013, 6, 69-95.

103. He, T.; Liang, S.; Song, D. Analysis of global land surface albedo climatology and spatial-temporal variation during 1981-2010 from multiple satellite products. J. Geophys. Res. Atmos. 2014, 119, 10281-10298.

104. Liu, J.; Schaaf, C.; Strahler, A.; Jiao, Z.; Shuai, Y.; Zhang, Q.; Roman, M.; Augustine, J.A.; Dutton, E.G. Validation of Moderate Resolution Imaging Spectroradiometer (MODIS) albedo retrieval algorithm: Dependence of albedo on solar zenith angle. J. Geophys. Res. 2009, 114, doi:10.1029/2008JD009969.

105. Salomon, J.G.; Schaaf, C.B.; Strahler, A.H.; Gao, F.; Jin, Y. Validation of the MODIS bidirectional reflectance distribution function and albedo retrievals using combined observations from the aqua and terra platforms. IEEE Trans. Geosci. Remote Sens. 2006, 44, 1555-1565.

106. Román, M.O.; Schaaf, C.B.; Lewis, P.; Gao, F.; Anderson, G.P.; Privette, J.L.; Strahler, A.H.; Woodcock, C.E.; Barnsley, M. Assessing the coupling between surface albedo derived from MODIS and the fraction of diffuse skylight over spatially-characterized landscapes. Remote Sens. Environ. 2010, 114, 738-760.

107. Schaaf, C.B.; Wang, Z.; Strahler, A.H. Commentary on Wang and Zender-MODIS snow albedo bias at high solar zenith angles relative to theory and to in situ observations in Greenland. Remote Sens. Environ. 2011, 115, 1296-1300.

108. Wang, X.; Zender, C.S. MODIS snow albedo bias at high solar zenith angles relative to theory and to in situ observations in Greenland. Remote Sens. Environ. 2010, 114, 563-575.

109. Wang, Z. The Moderate-Resolution Imaging Spectroradiometer (MODIS) Reflectance Anisotropy and Albedo of Dormant and Snow-Covered Canopies. Ph.D Thesis, Boston University, Boston, MA, USA, 2011. 
110. Jin, Y.; Schaaf, C.B.; Gao, F.; Li, X.; Strahler, A.H.; Lucht, W.; Liang, S. Consistency of MODIS surface bidirectional reflectance distribution function and albedo retrievals: 1. Algorithm performance. J. Geophys. Res. Atmos. 2003, 108, doi:10.1029/2002JD002803.

111. Jin, Y.; Schaaf, C.B.; Woodcock, C.E.; Gao, F.; Li, X.; Strahler, A.H.; Lucht, W.; Liang, S. Consistency of modis surface bidirectional reflectance distribution function and albedo retrievals: 2. Validation. J. Geophys. Res. Atmos. 2003, 108, doi:10.1029/2002JD002804.

112. Shuai, Y.; Schaaf, C.B.; Strahler, A.H.; Liu, J.; Jiao, Z. Quality assessment of BRDF/albedo retrievals in MODIS operational system. Geophys. Res. Lett. 2008, 35, doi: 10.1029/2007GL032568.

113. Baldocchi, D.; Falge, E.; Gu, L.; Olson, R.; Hollinger, D.; Running, S.; Anthoni, P.; Bernhofer, C.; Davis, K.; Evans, R. Fluxnet: A new tool to study the temporal and spatial variability of ecosystem-scale carbon dioxide, water vapor, and energy flux densities. Bull. Am. Meteorol. Soc. 2001, 82, 2415-2434.

114. Ohmura, A.; Gilgen, H.; Hegner, H.; Müller, G.; Wild, M.; Dutton, E.G.; Forgan, B.; Fröhlich, C.; Philipona, R.; Heimo, A. Baseline Surface Radiation Network (BSRN/WCRP): New precision radiometry for climate research. Bull. Am. Meteorol. Soc. 1998, 79, 2115-2136.

115. Augustine, J.A.; DeLuisi, J.J.; Long, C.N. SURFRAD-A national surface radiation budget network for atmospheric research. Bull. Am. Meteorol. Soc. 2000, 81, 2341-2357.

116. Steffen, K.; Box, J.; Abdalati, W. Greenland Climate Network (GC-Net). Available online: http://cires.colorado.edu/science/groups/steffen/gcnet/ (accessed on 8 October 2014).

117. Cescatti, A.; Marcolla, B.; Santhana Vannan, S.K.; Pan, J.Y.; Román, M.O.; Yang, X.; Ciais, P.; Cook, R.B.; Law, B.E.; Matteucci, G. Intercomparison of MODIS albedo retrievals and in situ measurements across the global fluxnet network. Remote Sens. Environ. 2012, 121, 323-334.

118. Liu, N.; Liu, Q.; Wang, L.; Liang, S.; Wen, J.; Qu, Y.; Liu, S. A statistics-based temporal filter algorithm to map spatiotemporally continuous shortwave albedo from MODIS data. Hydrol. Earth Syst. Sci. 2013, 17, 2121-2129.

119. Ju, J.; Roy, D.P.; Shuai, Y.; Schaaf, C. Development of an approach for generation of temporally complete daily nadir MODIS reflectance time series. Remote Sens. Environ. 2010, 114, 1-20.

120. Samain, O.; Geiger, B.; Roujean, J.L. Spectral normalization and fusion of optical sensors for the retrieval of BRDF and albedo: Application to VEGETATION, MODIS, and MERIS data sets. IEEE Trans. Geosci. Remote Sens. 2006, 44, 3166-3179.

121. Quaife, T.; Lewis, P. Temporal constraints on linear BRDF model parameters. IEEE Trans. Geosci. Remote Sens. 2010, 48, 2445-2450.

122. Moody, E.G.; King, M.D.; Platnick, S.; Schaaf, C.B.; Gao, F. Spatially complete global spectral surface albedos: Value-added datasets derived from terra MODIS land products. IEEE Trans. Geosci. Remote Sens. 2005, 43, 144-158.

123. Fang, H.; Liang, S.; Kim, H.Y.; Townshend, J.R.; Schaaf, C.L.; Strahler, A.H.; Dickinson, R.E. Developing a spatially continuous $1 \mathrm{~km}$ surface albedo data set over North America from terra MODIS products. J. Geophys. Res. Atmos. 2007, 112, doi:10.1029/2006JD008377.

124. Fang, H.; Liang, S.; Townshend, J.R.; Dickinson, R.E. Spatially and temporally continuous LAI data sets based on an integrated filtering method: Examples from North America. Remote Sens. Environ. 2008, 112, 75-93. 
125. Shuai, Y.; Masek, J.G.; Gao, F.; Schaaf, C.B. An algorithm for the retrieval of 30-m snow-free albedo from Landsat surface reflectance and MODIS BRDF. Remote Sens. Environ. 2011, 115, 2204-2216.

126. Shuai, Y.; Masek, J.G.; Gao, F.; Schaaf, C.B.; He, T. An approach for the long-term 30-m land surface snow-free albedo retrieval from historic Landsat surface reflectance and MODIS-based a priori anisotropy knowledge. Remote Sens. Environ. 2014, 152, 467-479.

127. Barnsley, M.J.; Settle, J.J.; Cutter, M.A.; Lobb, D.R.; Teston, F. The PROBA/CHRIS mission: A low-cost smallsat for hyperspectral multiangle observations of the earth surface and atmosphere. IEEE Trans. Geosci. Remote Sens. 2004, 42, 1512-1520.

128. Gao, B.; Jia, L.; Menenti, M. An improved method for retrieving land surface albedo over rugged terrain. IEEE Geosci. Remote Sens. Lett. 2014, 11, 554-558.

129. He, T.; Liang, S.; Wang, D.; Shuai, Y.; Yu, Y. Fusion of satellite land surface albedo products across scales using a multiresolution tree method in the North Central United States. IEEE Trans. Geosci. Remote Sens. 2014, 52, 3428-3439.

130. Faizal, M.; Ahmed, M.R. On the ocean heat budget and ocean thermal energy conversion. Int. J. Energy Res. 2011, 35, 1119-1144.

131. Perovich, D.; Grenfell, T.; Light, B.; Hobbs, P. Seasonal evolution of the albedo of multiyear Arctic sea ice. J. Geophys. Res. 2002, 107, 8044.

132. Riihelä, A.; Manninen, T.; Laine, V. Observed changes in the albedo of the Arctic sea-ice zone for the period 1982-2009. Nat. Clim. Change 2013, 3, 895-898.

133. Perovich, D.K.; Tucker, W.B.; Ligett, K.A. Aerial observations of the evolution of ice surface conditions during summer. J. Geophys. Res. Oceans 2002, 107, doi:8010.1029/2000JC000449.

134. Grenfell, T.C.; Warren, S.G.; Mullen, P.C. Reflection of solar radiation by the Antarctic snow surface at ultraviolet, visible, and near-infrared wavelengths. J. Geophys. Res. Atmos. 2012, 99, 18669-18684.

135. Sayer, A.; Thomas, G.; Grainger, R. A sea surface reflectance model for (A) ATSR, and application to aerosol retrievals. Atmos. Meas. Tech. 2010, 3, 1023-1098.

136. Briegleb, B.P.; Ramanathan, V.; Harrison, E.; Minnis, P. Comparison of regional clear-sky albedos inferred from satellite observations and model computations. J. Clim. Appl. Meteorol. 1986, 25, 214-226.

137. Hansen, J.; Russell, G.; Rind, D.; Stone, P.; Lacis, A.; Lebedeff, S.; Ruedy, R.; Travis, L. Efficient three-dimensional global models for climate studies: Models I and II. Mon. Weather Rev. 1983, 111, 609-662.

138. Cox, C.; Munk, W. Measurement of the roughness of the sea surface from photographs of the sun's glitter. J. Opt. Soc. Am. 1954, 44, 838-850.

139. Køltzow, M. The effect of a new snow and sea ice albedo scheme on regional climate model simulations. J. Geophys. Res. Atmos. 2007, 112, doi:07110.01029/02006JD007693.

140. Jin, Z.; Charlock, T.P.; Smith, W.L.; Rutledge, K. A parameterization of ocean surface albedo. Geophys. Res. Lett. 2004, 31, doi:10.1029/2004GL021180.

141. Qu, Y.; Liang, S.; Liu, Q.; Li, X.; Liu, S. Estimating shortwave Arctic sea-ice albedo from MODIS data. IEEE Trans. Geosci. Remote Sens. 2015, submitted. 
142. Feng, Y.; Liu, Q.; Qu, Y.; Liang, S. Estimation of the ocean water albedo from remote sensing and meteorological reanalysis data. IEEE Trans. Geosci. Remote Sens. 2015, submitted.

143. Liu, Q.; Wen, J.; Qu, Y.; He, T.; Zhang, X. Broadband albedo. In Advanced Remote Sensing: Terrestrial Information Extraction and Applications; Liang, S., Wang, J., Li, X., Eds; Academic press: San Diego, CA, USA, 2012.

144. Wen, J.; Zhao, X.; Liu, Q.; Tang, Y.; Dou, B. An improved land-surface albedo algorithm with DEM in rugged terrain. IEEE Geosci. Remote Sens. Lett. 2010, 11, 883-887.

145. Yang, J.; Gong, P.; Fu, R.; Zhang, M.; Chen, J.; Liang, S.; Xu, B.; Shi, J.; Dickinson, R. The role of satellite remote sensing in climate change studies. Nat. Clim. Change 2013, 3, 875-883.

146. Nicodemus, F.; Richmond, J.; Hsia, J.; Ginsberg, I.; Limperis, T. Geometrical Considerations and Nomenclature for Reflectance; National Bureau of Standards: Washington, DC, USA, 1977.

147. Lyapustin, A.; Privette, J. A new method of retrieving surface bidirectional reflectance from ground measurements: Atmospheric sensitivity study. J. Geophys. Res. 1999, 104, 6257-6268.

148. Lewis, P.; Barnsley, M. Influence of the sky radiance distribution on various formulations of the earth surface albedo. In Proceedings of 6th International Symposium on Physical Measurements and Signatures in Remote Sensing, Val d'Isere, France, 1 January 1994; pp. 707-715.

149. Pinty, B.; Lattanzio, A.; Martonchik, J.V.; Verstraete, M.M.; Gobron, N.; Taberner, M.; Widlowski, J.-L.; Dickinson, R.E.; Govaerts, Y. Coupling diffuse sky radiation and surface albedo. J. Atmos. Sci. 2008, 62, 2580-2591.

150. Minnaert, M. The reciprocity principle in lunar photometry. Astrophys. J. 1941, 93, 403-410.

151. Shibayama, M.; Wiegand, C. View azimuth and zenith, and solar angle effects on wheat canopy reflectance. Remote Sens. Environ. 1985, 18, 91-103.

152. Walthall, C.; Norman, J.; Welles, J.; Campbell, G.; Blad, B. Simple equation to approximate the bidirectional reflectance from vegetative canopies and bare soil surfaces. Appl. Opt. 1985, 24, 383-387.

153. Staylor, W.F.; Suttles, J.T. Reflection and emission models for deserts derived from Nimbus-7 ERB scanner measurements. J. Appl. Meteorol. 1986, 25, 196-202.

154. Wanner, W.; Li, X.; Strahler, A. On the derivation of kernels for kernel-driven models of bidirectional reflectance. J. Geophys. Res. 1995, 100, 21077-21090.

155. Schaepman-Strub, G.; Schaepman, M.; Painter, T.; Dangel, S.; Martonchik, J. Reflectance quantities in optical remote sensing-Definitions and case studies. Remote Sens. Environ. 2006, 103, 27-42. 
156. Strahler, A.; Muller, J.; Lucht, W.; Schaaf, C.; Tsang, T.; Gao, F.; Li, X.; Lewis, P.; Barnsley, M. MODIS BRDF/Albedo Product: Algorithm Theoretical Basis Document Version 5.0. Available online: http://www.researchgate.net/publication/234144971_MODIS_BRDF_Albedo_ Product_ATBD_V_5.0 (accessed on 8 October 2014).

(C) 2015 by the authors; licensee MDPI, Basel, Switzerland. This article is an open access article distributed under the terms and conditions of the Creative Commons Attribution license (http://creativecommons.org/licenses/by/4.0/). 